University of Wollongong

Research Online

Faculty of Engineering and Information

Faculty of Engineering and Information

Sciences - Papers: Part B

Sciences

2018

\title{
Nucleation, coarsening and deformation accommodation mechanisms of $\varepsilon$-martensite in a high manganese steel
}

Sudipta Pramanik

University of Wollongong, sp345@uowmail.edu.au

Azdiar Adil Gazder

University of Wollongong, azdiar@uow.edu.au

Ahmed A. Saleh

University of Wollongong, asaleh@uow.edu.au

Elena V. Pereloma

University of Wollongong, elenap@uow.edu.au

Follow this and additional works at: https://ro.uow.edu.au/eispapers1

Part of the Engineering Commons, and the Science and Technology Studies Commons

Research Online is the open access institutional repository for the University of Wollongong. For further information contact the UOW Library: research-pubs@uow.edu.au 


\title{
Nucleation, coarsening and deformation accommodation mechanisms of $\varepsilon$ - martensite in a high manganese steel
}

\author{
Abstract \\ The nucleation, coarsening and deformation accommodation mechanisms of $\varepsilon$-martensite in an \\ Fe-17Mn-3Al-2Si-1Ni-0.06C wt.\% high manganese steel subjected to plane strain compression and cold- \\ rolling up to $88 \%$ thickness reduction was studied using a combination of electron microscopy \\ techniques. \\ Disciplines \\ Engineering | Science and Technology Studies

\section{Publication Details} \\ Pramanik, S., Gazder, A. A., Saleh, A. A. \& Pereloma, E. V. (2018). Nucleation, coarsening and deformation \\ accommodation mechanisms of $\varepsilon$-martensite in a high manganese steel. Materials Science and \\ Engineering A: Structural Materials: Properties, Microstructure and Processing, 731 506-519.
}




\title{
Nucleation, coarsening and deformation accommodation mechanisms of $\varepsilon$-martensite in a high manganese steel
}

\author{
Sudipta Pramanik ${ }^{1}$, Azdiar A. Gazder², Ahmed A. Saleh¹, Elena V. Pereloma ${ }^{1,2}$ \\ ${ }^{1}$ School of Mechanical, Materials, Mechatronic and Biomedical Engineering, University of \\ Wollongong, New South Wales 2522, Australia \\ 2Electron Microscopy Centre, University of Wollongong, New South Wales 2500, Australia
}

\begin{abstract}
The nucleation, coarsening and deformation accommodation mechanisms of $\varepsilon$-martensite in an Fe-17Mn-3Al-2Si-1Ni-0.06C wt.\% high manganese steel subjected to plane strain compression and coldrolling up to $88 \%$ thickness reduction was studied using a combination of electron microscopy techniques. Intrinsic stacking faults in $\gamma$-austenite led to the nucleation of fine deformation-induced $\varepsilon$ martensite laths. In accordance with previous observations, the lateral coarsening of deformationinduced $\varepsilon$-martensite laths occurred via their coalescence with neighbouring $\varepsilon$-martensite plates/laths. Electron back-scattering diffraction and high-angle annular dark-field observations showed that $\varepsilon$ martensite accommodates deformation via a combination of perfect and partial basal slip, pyramidal slip and $\{10 \overline{1} 2\}\langle\overline{1} 011\rangle_{\varepsilon}$ extension twinning. The operation of partial basal slip; generating $\mathrm{I}_{1}$ and $\mathrm{I}_{2}$-type basal stacking faults at smaller thickness reductions and thereafter, only $\mathrm{I}_{1}$-type stacking faults at larger thickness reductions was observed in $\varepsilon$-martensite. Consequently, a mechanism that enables a transition from $\varepsilon$-martensite $I_{2}$ to $I_{1}$-type stacking faults is proposed.
\end{abstract}

Keywords: electron microscopy; stress/strain measurements; iron alloys; phase transformations; plasticity 


\section{Introduction}

Advanced high strength steels with manganese (Mn) content between 15-20 wt.\% exhibits a unique combination of high strength and ductility. Therefore, they are suitable candidates for utilisation in automobile bodies in order to reduce their weight and consequently meet the stringent requirements of better fuel economy and lesser $\mathrm{CO}_{2}$ emissions. These steels possess low stacking fault energies $(\gamma$-SFE, $\sim 10$ to $40 \mathrm{~mJ} / \mathrm{m}^{2}$ ) $[1,2]$ and comprise a metastable face-centred cubic (fcc) austenite $(\gamma)$ phase. Depending on the exact value of $\gamma$-SFE, $\gamma$ accommodates room temperature deformation by a combination of perfect and partial slip, deformation twinning and the phase transformation to hexagonal closed packed (hcp) $\varepsilon$-martensite and/or body-centred cubic (bcc) $\alpha^{\prime}$-martensite [3-5].

In the $\gamma$ phase, deformation accommodation by the dissociation of perfect dislocations into Shockley partial dislocations generates a stacking faults that subsequently leads to deformation twinning and/or $\varepsilon$-martensite formation. Here deformation twinning or $\varepsilon$-martensite formation occurs by the motion of Shockley partial dislocations on successive or alternating (111) $)_{\gamma}$ planes, respectively [6, 7].

Cold-rolling [4, 8-10] and uniaxial tension [11-13] studies have shown that phase transformation from the $\gamma$ phase to the $\alpha^{\prime}$-martensite phase follows two pathways: (i) $\gamma \rightarrow \varepsilon \rightarrow \alpha^{\prime}$ or, (ii) $\gamma \rightarrow \alpha^{\prime}[14,15]$. The $\alpha^{\prime}$-martensite formation is favoured at local regions of high dislocation density in $\gamma$ grains such as slip bands or at the intersection of $\gamma$ deformation twins and $\varepsilon$-martensite laths $[6,8,16,17]$. Additional deformation in $\alpha^{\prime}$-martensite is accommodated by slip and a combination of macro and shear banding.

While a number of studies have focussed on the characterisation of deformation mechanisms in the $\gamma$ and $\alpha^{\prime}$-martensite phases $[9,18,19]$, relatively limited investigations have studied the deformation of $\varepsilon$-martensite. In general, stacking faults in the hcp phase is created by the motion of Shockley partial dislocations on the $(0001)_{\varepsilon}$ basal plane that is classified as (i) intrinsic stacking faults ( $\varepsilon$-ISFs), (ii) extrinsic stacking faults ( $\varepsilon$-ESFs), or (iii) $\varepsilon$-twin faults.

$\varepsilon$-ISFs are of two types namely, $\mathrm{I}_{1}$ and $\mathrm{I}_{2}$. In general, the dislocation reactions for the formation of $I_{1}$ and $I_{2} \varepsilon$ - ISFs are equivalent to the dissociation of a perfect dislocation into two Shockley partials. An $I_{1}$ type $\varepsilon$-ISF occurs by the removal of one layer of basal plane atoms followed by slip along $\frac{a}{3}[10 \overline{1} 0]_{\varepsilon}[20]$. The process is described as $\mathrm{ABABABAB} \rightarrow \mathrm{ABAB} \mid \mathrm{CBCB}$. An $\mathrm{I}_{2}$ type $\varepsilon$-ISF is facilitated by the motion of $\frac{a}{3}[10 \overline{1} 0]_{\varepsilon}$ Shockley partial dislocations and is described as $A B A B A B A B \rightarrow A B A B|C| A C A C$.

The formation of $\varepsilon$-ESFs occurs by the glide of two Shockley partial dislocations with Burgers vectors $\frac{\mathrm{a}}{3}[10 \overline{1} 0]_{\varepsilon}$ of opposite sign on the top and bottom adjoining basal planes [21]. This dislocation motion changes the stacking sequence from $\mathrm{ABABABAB} \rightarrow \mathrm{ABAB}|\mathrm{C}| \mathrm{ABAB}$ or $\mathrm{BABABABA} \rightarrow \mathrm{BABA} \mid \mathrm{CBCB}$; without altering the nearest-neighbour arrangement of the hcp stacking sequence. The dislocation reaction for the formation of extrinsic stacking faults is represented as [21] :

$\frac{\mathrm{a}}{2}[0001]_{\varepsilon}+\frac{\mathrm{a}}{3}[10 \overline{1} 0]_{\varepsilon}+\frac{\mathrm{a}}{3}[\overline{1} 010]_{\varepsilon} \rightarrow \frac{\mathrm{a}}{2}[0001]_{\varepsilon}$

Since the fault energy associated with $\varepsilon$-ESFs is three times greater than $\varepsilon$-ISFs [21], $\varepsilon$-ESFs can convert to $\mathrm{I}_{1}$-type $\varepsilon$-ISFs via the following reaction: 


$$
\frac{\mathrm{a}}{3}[10 \overline{1} 0]_{\varepsilon}+\frac{\mathrm{a}}{2}[0001]_{\varepsilon} \rightarrow \frac{\mathrm{a}}{6}[20 \overline{2} 3]_{\varepsilon}
$$

The third and more uncommon fault type in the hcp phase is a twin fault, which is noted for its mirror symmetry about the basal plane. The formation of twin faults has been described by the shearing

of subsequent basal planes by dislocations with a Burger vector $\frac{\mathrm{a}}{3}[10 \overline{1} 0]_{\varepsilon}[22]$. The atomic stacking across twin faults is described as $\mathrm{ABABABAB} \rightarrow \mathrm{ABAB}|\mathrm{C}| \mathrm{BABA}[23]$.

While the feasibility of $\varepsilon$-martensite to accommodate deformation was first discussed in Refs. [24, 25] based on transmission Kikuchi diffraction micro-texture analysis and neutron diffraction work, no detailed microstructural characterisation was undertaken. Kim et al. [26] observed dislocations with a $\langle c\rangle$ component in $\varepsilon$-martensite which dissociate into Shockley partial dislocations in the basal plane to accommodate deformation during tensile testing of an Fe-17Mn steel to 0.05 engineering strain. Using Xray diffraction peak analysis of an Fe-17Mn-0.02C steel, an earlier study suggested that $\varepsilon$-ISFs are behind its reverse transformation back to the $\gamma$ phase during tensile deformation [27]. In an Fe-14Mn-6Si-9Cr$5 \mathrm{Ni}$ shape memory alloy cold-rolled to $10 \%$ thickness reduction and annealed at $697{ }^{\circ} \mathrm{C}$ for $600 \mathrm{~s}$, the presence of an immobile, 3-5 atomic layers wide, fcc stacking sequence within the $\varepsilon$-martensite phase was reported as the possible reason behind the resistance to shape change during fcc to hcp phase transformations [28]. In that study, the fcc stacking sequence was summarised to be a remnant of the parent $\gamma$ phase due to the local incomplete motion of Shockley partials on alternate $(111)_{\gamma}$ planes. Another investigation found that while Shockley partial dislocations created the $\varepsilon$-martensite lath in an Fe-18Mn-0.25C-0.084N steel, different dislocation reactions were responsible for the creation of stacking faults; particularly in conjunction with stress relief during subsequent $\alpha^{\prime}$-martensite nucleation at the intersection of two $\varepsilon$-martensite laths [6]. The last study did not report the character of the stacking faults for each fault type in $\varepsilon$-martensite.

From the above, it is clear that questions remain as to the character and role of stacking faults during the nucleation, coarsening and deformation of $\varepsilon$-martensite. With respect to this outlook, the present study is the first to use a combination of electron back-scattering diffraction (EBSD), transmission electron microscopy (TEM), high-angle annular dark-field (HAADF) and atomic resolution scanning-transmission electron microscopy (STEM) to elucidate the nucleation, coarsening and deformation accommodation mechanisms in $\varepsilon$-martensite for a high Mn steel subjected to up to $88 \%$ thickness reduction via plane strain compression and cold-rolling.

\section{Experimental and analytical procedure}

The composition of the investigated steel (Fe-17Mn-3Al-2Si-1Ni-0.06C wt.\%) was selected based on the occurrence of both $\varepsilon$ and $\alpha^{\prime}$-martensite formation during its deformation. The steel was cast in slabs of 245 (length) $\times 60$ (width) $\times 20.6$ (height) $\mathrm{mm}^{3}$. The slab was reheated to $1100{ }^{\circ} \mathrm{C}$ for $7200 \mathrm{~s}$. The homogenised slab was hot-rolled at $1100{ }^{\circ} \mathrm{C}$ to $52.5 \%$ thickness reduction in 4 passes. Hot-rolled rectangular samples of 8 (length) $\times 20$ (width) $\times 6$ (height) $\mathrm{mm}^{3}$ were subjected to plane strain compression to $5 \%, 10 \%, 15 \%, 20 \%$ thickness reduction using a Gleeble 3500 thermo-mechanical 
simulator. Rectangular hot-rolled strips of 516 (length) $\times 60$ (width) $\times \sim 9.8$ (height) $\mathrm{mm}^{3}$ were coldrolled under lubrication to $42 \%, 66 \%$ and $88 \%$ thickness reduction, using $4.8 \%$ thickness reduction per pass in a 4-high laboratory rolling mill with work roll dimeter of $350 \mathrm{~mm}$. Based on energy dispersive spectroscopy (EDS) analysis of the $42 \%$ cold-rolled condition, the distribution of alloying elements was homogenous as shown in supplementary Fig. S1.

An applied strain rate of $1.7 \times 10^{-2} \mathrm{~s}^{-1}$ was maintained constant during plane strain compression and cold-rolling. The raw load-displacement data obtained from the thermo-mechanical simulator was converted to equivalent stress and strain using the equations [29]:

$$
\begin{aligned}
& \varepsilon=(2 / \sqrt{3}) \ln \left(\mathrm{t} / \mathrm{t}_{0}\right) \\
& \sigma=\left(\frac{\sqrt{3}}{2}\right) \mathrm{F} / \mathrm{l}_{0} \mathrm{w}_{0}
\end{aligned}
$$

where, $\mathrm{l}_{0} \times \mathrm{w}_{0} \times \mathrm{t}_{0}=8 \times 20 \times 6 \mathrm{~mm}^{3}$ are the initial sample length, width and height that correspond to the rolling (RD), transverse (TD) and normal (ND) directions of the hot-rolled strip, respectively. The symbols $\mathrm{t}$ and $\mathrm{F}$ denote the instantaneous sample height and load, respectively.

Thin foils for EBSD and TEM work were prepared by punching $3 \mathrm{~mm}$ diameter discs from the RD$\mathrm{ND}$, ground up to 2400 grit and then twin-jet electropolished at $-25^{\circ} \mathrm{C}$ using a solution of $90 \%$ methanol and $10 \%$ perchloric acid in a Struers Tenupol-5 operating at $30 \mathrm{~V}(\sim 150 \mathrm{~mA})$.

The EBSD maps were collected using a JEOL JSM-7001F field emission gun scanning electron microscope operating at $15 \mathrm{kV}$ accelerating voltage and $\sim 6.5 \mathrm{nA}$ probe current at $12 \mathrm{~mm}$ working distance using a Nordlys-II(S) EBSD detector controlled by Oxford Instruments AZtec software. While the EBSD maps of the hot-rolled condition and the sample after $5 \%$ thickness reduction were acquired at a step size of $100 \mathrm{~nm}$, a step size of $30 \mathrm{~nm}$ was maintained constant for all other conditions. The areas of the EBSD maps were $142 \times 106 \mu \mathrm{m}^{2}$ for the hot-rolled condition, $120 \times 90 \mu \mathrm{m}^{2}$ for the sample after $5 \%$ thickness reduction and $60 \times 45 \mu^{2}$ for the samples after $10-88 \%$ thickness reduction.

The EBSD maps were post-processed using Oxford Instruments Channel-5 software following the procedure described in Refs. [30-32]. In brief, it involved the removal of orientation spikes followed by cyclic extrapolation of zero solutions down to five neighbours followed by thresholding the band contrast to exclude regions with black band contrast where no indexing was possible. The red, blue, green and white colours in the phase maps denote the $\gamma, \alpha^{\prime}$ and $\varepsilon$-martensite phases and unindexed areas, respectively. Boundaries misorientations $(\theta)$ between $2^{\circ} \leq \theta<15^{\circ}$ are defined as low angle grain boundaries (LAGBs) while boundaries misorientations $\theta \geq 15^{\circ}$ denote high angle grain boundaries (HAGBs). $\Sigma 3$ twin boundaries in the $\gamma$ phase have a misorientation angle of $60^{\circ}$ about the $\langle 111\rangle_{\gamma}$ axis with a maximum deviation of $6.03^{\circ}$ calculated using the Palumbo-Aust criterion $\left(\Delta \theta \leq 15^{\circ} \Sigma^{-5 / 6}\right.$ [33]). $\{10 \overline{1} 2\}\langle\overline{1} 011\rangle_{\varepsilon}$ extension twins in $\varepsilon$-martensite have a misorientation angle of $\sim 86^{\circ} \pm 5^{\circ}$ about the $\langle 1 \overline{2} 10\rangle_{\varepsilon}$ axis [34].

TEM was undertaken at $200 \mathrm{kV}$ on a $\mathrm{LaB}_{6}$ JEOL JEM-2010 and a cold field emission gun JEOL JEMARM200F. Bright-field selected area electron diffraction patterns, and dark-field images were collected for all samples on both microscopes. 
Atomic resolution HAADF STEM micrographs were acquired on the JEOL JEM-ARM200F using its hexagonal probe corrector with 68 and 180 mrad inner and outer collection angles, respectively and cleaned using the HRTEM filter tool in the Gatan DigitalMicrograph software suite [35]. The widths of $\varepsilon$ martensite plates/laths $(\mathrm{w})$ were estimated using the measured widths $\left(\mathrm{w}_{\mathrm{L}}\right)$ from the TEM micrographs via the following equation [36]:

$$
\mathrm{w}=\frac{2 \mathrm{w}_{\mathrm{L}}}{\pi}
$$

\section{Results}

\subsection{Stress-strain curve during plane strain compression to 20\% thickness reduction}

Fig. 1a shows the equivalent stress-strain curve upon plane strain compression to $20 \%$ thickness reduction. The curve shows a deviation from linearity followed by a nearly plateau region and then a third region of approximately linearly increasing equivalent stress with strain. The start of the plateau region is conventionally linked to the onset of martensite transformation. Here a triggering stress of $\sim 229$ $\mathrm{MPa}$ is required for the onset of martensite transformation and is estimated by intersecting the elastic modulus tangent and the extension of the tangent to the plateau region [37]. While the concept of triggering stress has been mainly applied to phase transforming metastable $\beta$-Ti alloys, it has also been used for CrNi metastable austenitic stainless steel subjected to uniaxial tension [38]. The corresponding strain hardening curve given in Fig. $1 \mathrm{~b}$ also depicts three regions comprising an initial sharp decrease, an approximately constant region of hardening followed by increase in hardening. The first and second regions correspond to the elasto-plastic transition [39] and the onset of $\gamma$ phase transformation to deformation-induced $\varepsilon$ and $\alpha^{\prime}$-martensite. The increase in hardening in the third region is ascribed to: (i) a greater fraction of the $\gamma$ phase transforming to $\varepsilon$ and $\alpha^{\prime}$-martensite, (ii) a further transformation of $\varepsilon$ to $\alpha^{\prime}$-martensite, and (iii) load partitioning via deformation accommodation by all three phases.

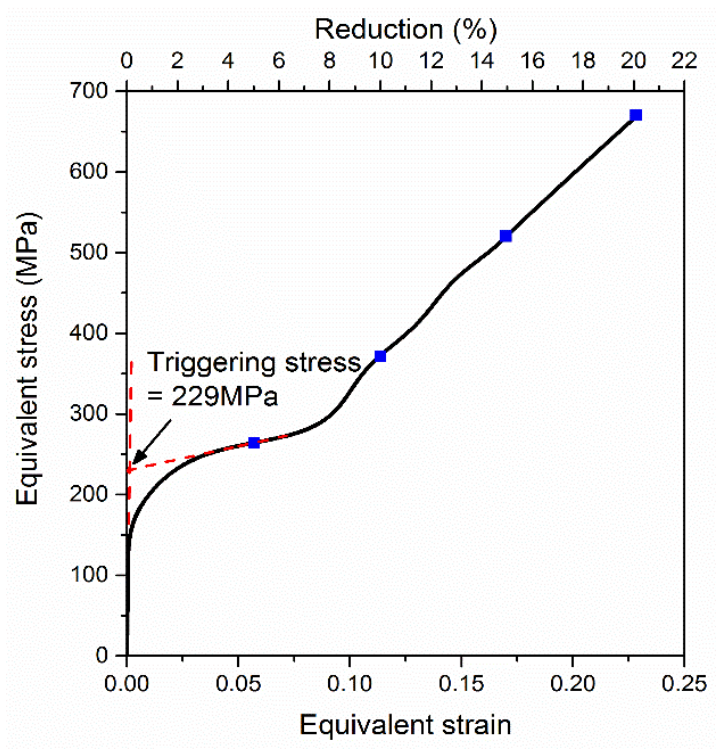

(a)

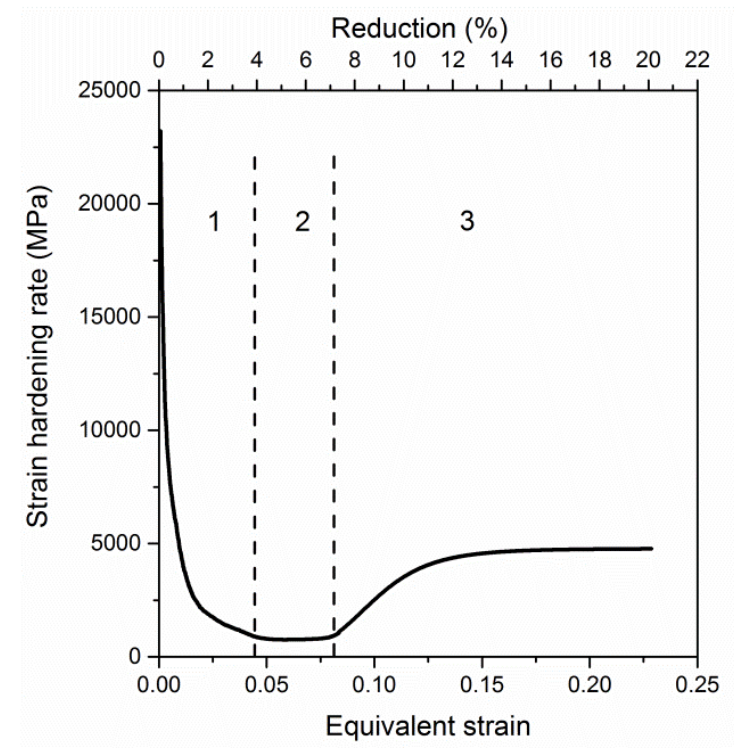

(b) 
Figure 1: Equivalent (a) stress-strain and (b) strain hardening curves upon plane strain compression to $20 \%$ thickness reduction. In Fig. 1 a the blue squares correspond to $5 \%, 10 \%, 15 \%$ and $20 \%$ thickness reductions. The red dashed lines are used to calculate the triggering stress by intersecting the elastic modulus tangent and the extension of the tangent to the plateau region.

\subsection{Microstructure evolution with thickness reduction}

Figs. 2a-2h are superimposed band contrast and phase maps after hot-rolling and plane strain compression/cold-rolling up to $88 \%$ thickness reduction. The hot-rolled microstructure comprises coarse $\gamma$ grains with annealing twins as well as $\varepsilon$ and $\alpha^{\prime}$-martensite that formed on quenching from $1100{ }^{\circ} \mathrm{C}$. In this regard, the $\varepsilon$-martensite transformation start temperature was calculated for the present Fe-17Mn3Al-2Si-1Ni-0.06C steel by Dafé et al. [40] based on the equation proposed by Yang et al. [41]: $\mathrm{M}_{\mathrm{S}}(\mathrm{K})=576-489($ wt. \% C) - 9.1(wt. \% Mn) - 17.6(wt. \% Ni) - 9.2(wt. \% Cr) + 21.3(wt. \% Al) + 4.1 (wt. \% Si) - 19.4(wt. \% Mo) - 1(wt. \% Co) - 41.3(wt. \% Cu) - 50(wt. \% Nb) - 86(wt. \% Ti) $4($ wt. \% V) $-13($ wt. \% W)

The calculated $\varepsilon$-martensite start temperature is $174{ }^{\circ} \mathrm{C}$, which is well above the room temperature. The $\alpha^{\prime}$-martensite transformation start temperature was also calculated to be $\sim 72{ }^{\circ} \mathrm{C}$ from the following empirical equation used for Mn containing steels [42]:

$$
\mathrm{M}_{\mathrm{S}}\left({ }^{\circ} \mathrm{C}\right)=539-423(\text { wt. \% C) }-30.4(\text { wt. \% Mn })-7.5(\text { wt. \% Si })+30(\text { wt. \% Al) }
$$

It follows that the formation of $\varepsilon$ and $\alpha^{\prime}$-martensite upon water quenching after hot-rolling is expected.

As shown by the inset in Fig. 2a, the dark lines within $\gamma$ grains that do not have a misorientation angle across their bounds are most likely stacking faults carried over from hot-rolling [43]. The morphology of $\varepsilon$-martensite formed upon quenching is in the form of long thin laths or coarse plates running across $\gamma$ grains. Within any $\gamma$ grain, parallel and intersecting $\varepsilon$-martensite plates belong to the same or different hcp variants, respectively. The majority of $\alpha^{\prime}$-martensite grains formed on quenching are within thick $\varepsilon$-martensite plates. The formation of $\alpha^{\prime}$-martensite from $\varepsilon$-martensite has been observed in an Fe-15Mn-0.5C (wt.\%) high Mn steel after solution treatment at $1000{ }^{\circ} \mathrm{C}$ for $1 \mathrm{~h}$ followed by water quenching [44].

Figs. $2 \mathrm{~b}-2 \mathrm{~h}$ are representative of microstructure evolution with increasing thickness reduction. The retention of coarse $\gamma$ grains along with $\Sigma 3$ annealing twins carried over from hot-rolling is noted up to $20 \%$ thickness reduction (Figs. $2 \mathrm{~b}-2 \mathrm{e}$ ). It can be seen that a higher fraction of quenched $\varepsilon$ and $\alpha^{\prime}$ martensite is associated with coarser $\gamma$ grains due to the higher surface area available for the nucleation and subsequent growth (see the coarser $\gamma$ grains in Fig. 2b) within $\gamma$ grains, the formation of fine deformation-induced $\varepsilon$-martensite laths occurs at: (i) $\gamma$ stacking faults, as shown by a white arrow in the top right inset in Fig. $2 \mathrm{~b}$ (here $\gamma$ regions with darker band contrast have been verified via TEM to be associated with stacking faults [45]), or (ii) $\gamma \Sigma 3$ annealing twin boundaries as shown in the top right inset (1) in Fig. 2d. 
Within $\varepsilon$-martensite grains, $\{10 \overline{1} 2\}\langle\overline{1} 011\rangle_{\varepsilon}$ extension twins with $\sim 86^{\circ}$ misorientation angle are denoted in fuchsia and shown in the bottom left inset (2) in Fig. 2d. The formation of deformationinduced $\alpha^{\prime}$-martensite occurs in: (i) a lenticular and plate morphology within the thick $\varepsilon$-martensite plates which are carried over from quenching after hot-rolling or formed during cold deformation (Fig. 2e), or (ii) a blocky morphology at the intersection of two $\varepsilon$-martensite laths as shown in the top left inset (1) in Fig. 2e and at $\gamma$ grain boundaries as shown in the bottom left inset (2) in Fig. 2e. Due to the subdivision of the $\varepsilon$-martensite plates (carried over after hot-rolling or formed during cold deformation) by white arrows colonies of deformation-induced $\alpha^{\prime}$-martensite, the remnant $\varepsilon$-martensite has a blocky morphology as shown in the bottom left inset (2) and top right inset (3) in Fig. 2e.

At $42 \%$ thickness reduction, the microstructure returned a majority $\alpha^{\prime}$-martensite phase fraction followed by a minor $\varepsilon$-martensite phase fraction and a trace amounts of untransformed $\gamma$ (Fig. 2f). 66\% thickness reduction resulted in an even larger phase fraction of $\alpha^{\prime}$-martensite and trace areas of $\varepsilon$ martensite and untransformed $\gamma$ (to locate the $\gamma$ phase refer to the arrows in Fig. $2 \mathrm{~g}$ ). It is interesting to note that $\varepsilon$-martensite undergoes a change in morphology from blocky to elongated grains after $42 \%$ and $66 \%$ thickness reduction, respectively. This hints at $\varepsilon$-martensite accommodating deformation while undergoing transformation to $\alpha^{\prime}$-martensite.

Thickness reduction from $42 \%$ to $88 \%$ returned an $\alpha^{\prime}$-martensite microstructure whose grains widths decreased from $0.26 \pm 0.1$ to $0.15 \pm 0.12 \mu \mathrm{m}$ when measured via the linear intercept method along the ND. In Fig. $2 \mathrm{~h}$, the white areas denote unindexed regions as well as regions of highly localised strain such as macroscopic shear bands.

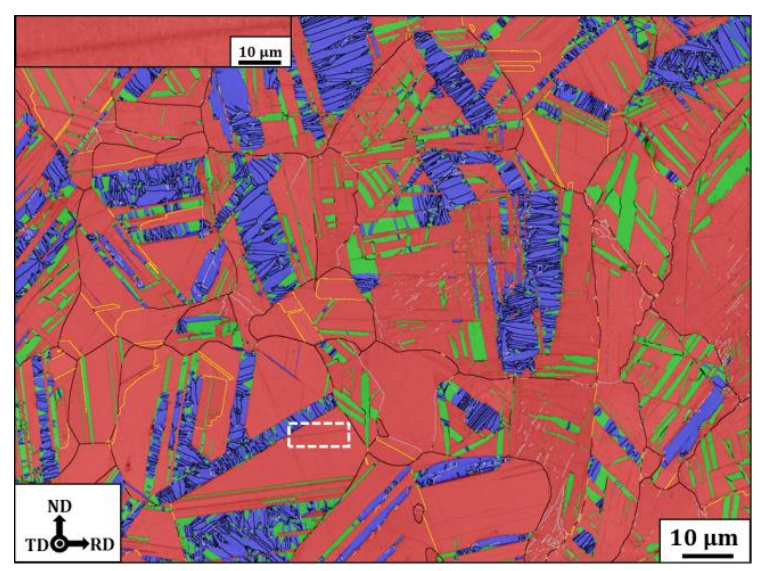

(a)

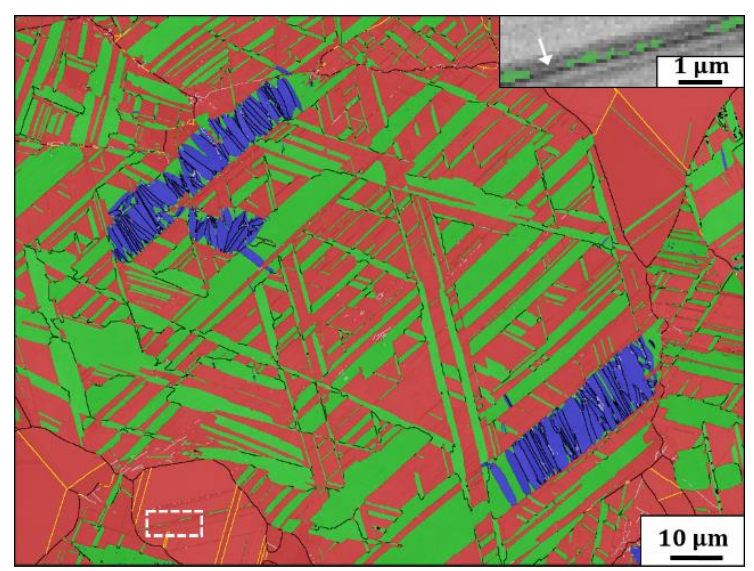

(b) 


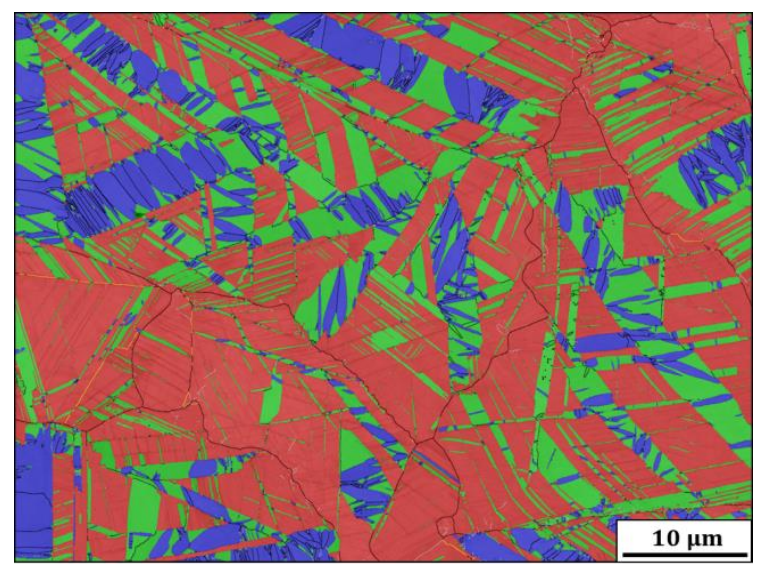

(c)

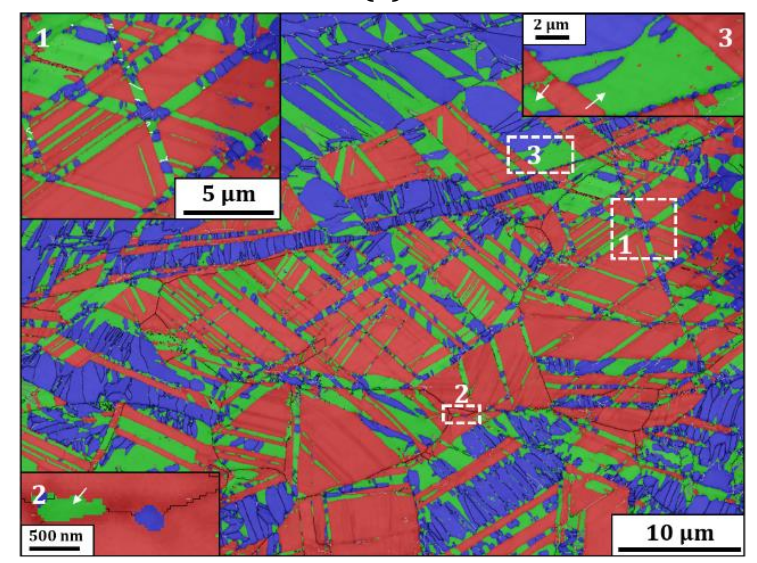

(e)

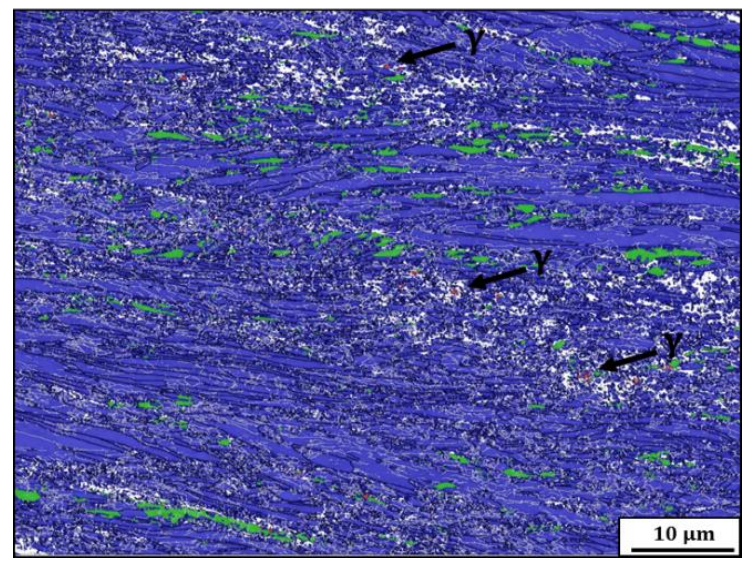

(g)

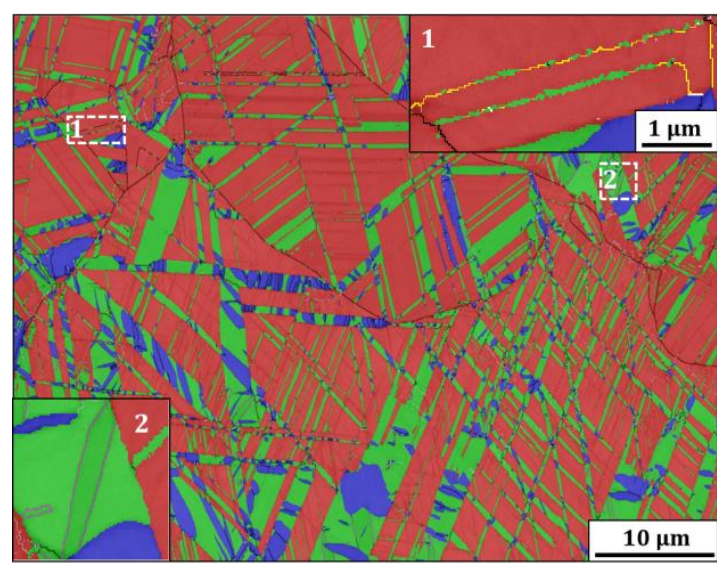

(d)

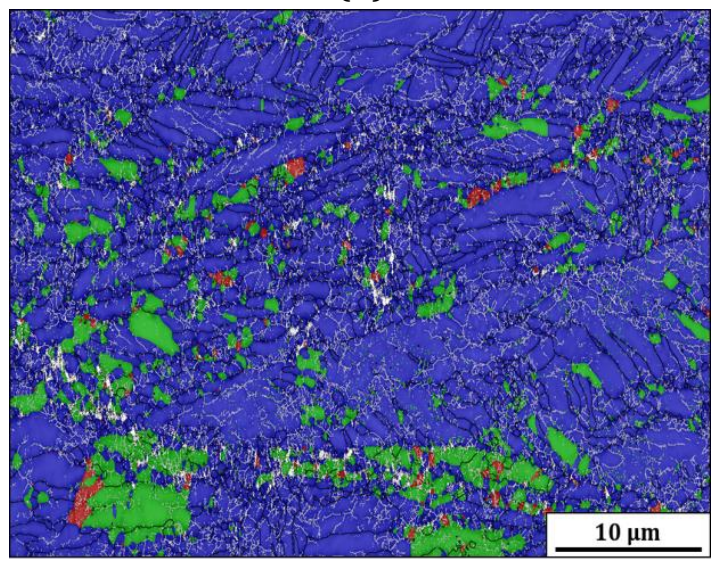

(f)

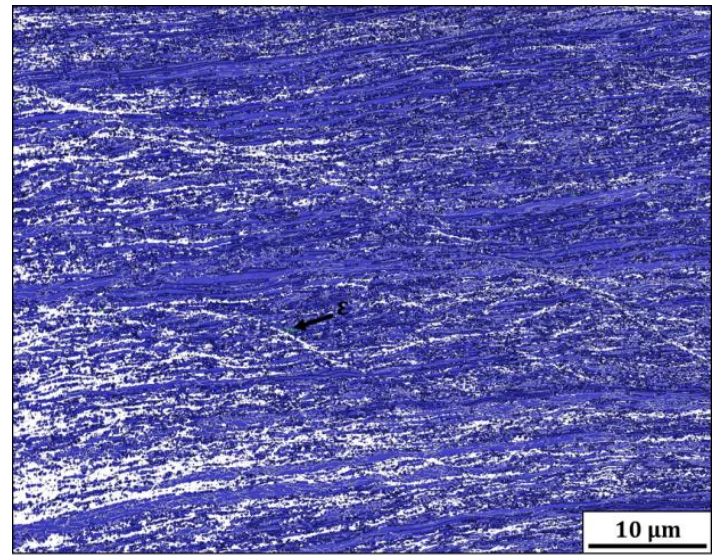

(h)

Figure 2: Superimposed band contrast and phase maps after (a) hot-rolling and room temperature thickness reduction to (b) 5\%, (c) 10\%, (d) 15\%, (e) 20\%, (f) 42\%, (g) 66\% and (h) 88\%. Red = $\gamma$, green $=\varepsilon$-martensite, blue $=\alpha^{\prime}$-martensite, white $=$ unindexed areas, silver $=$ low-angle grain boundaries, black $=$ high-angle grain boundaries, yellow $=\gamma$ twin boundaries. Rolling direction (RD) $=$ horizontal. Insets 1 , 2 in Figs. 2d and 1-3 in Figs. 2e are magnified views of regions highlighted by the corresponding white dashed rectangles 1, 2 and 1-3. White arrow in inset Fig. $2 \mathrm{~b}$ indicates $\gamma$ stacking faults. White arrows in inset (2) and (3) in Fig. 2e indicates blocky $\varepsilon$-martensite.

Figs. 3a-3c are the misorientation angle distributions of the three phases after plane strain compression and cold-rolling. With larger thickness reduction, the $\gamma$ phase recorded an increase in LAGB 
fraction from $\sim 0.14$ to 0.97 and a decreasing fraction of $\Sigma 3$ twin boundaries (Fig. 3a). This decrease in the $\Sigma 3$ twin boundary fraction is primarily associated with a deviation away from the Palumbo-Aust criterion due to the continued accumulation of dislocations at twin boundaries [46] as well as the nucleation of $\varepsilon$ martensite at twin boundaries.

In Fig. $3 \mathrm{~b}$, the $\varepsilon$-martensite phase returned high fractions of LAGBs and boundaries with misorientation angle/axis of $70^{\circ} /\langle 11 \overline{2} 0\rangle_{\varepsilon}$. The latter corresponds to high-angle inter-variant boundaries between $\varepsilon$-martensite plates/laths $[47,48]$; whose fraction decreases with larger thickness reduction and transformation to $\alpha^{\prime}$-martensite. Smaller HAGB fractions are also noted at $86^{\circ}$ and $90^{\circ}$ with misorientation axes $\sim\langle 11 \overline{2} 0\rangle_{\varepsilon}$. Similar to the $\Sigma 3$ twins boundaries in the $\gamma$ phase, these $\{10 \overline{1} 2\}\langle\overline{1} 011\rangle_{\varepsilon}$ extension twins deviate away from their ideal misorientation angle/axis with larger thickness reduction. The LAGB population is observed to increase with thickness reduction.

In Fig. 3c, the $\alpha^{\prime}$-martensite phase records misorientation peaks at $10^{\circ} /\langle 110\rangle_{\alpha^{\prime}}, 50^{\circ} /\langle 110\rangle_{\alpha^{\prime}}$, $60^{\circ} /\langle 110\rangle_{\alpha^{\prime}}$ and $60^{\circ} /\langle 111\rangle_{\alpha^{\prime}}$; all of which correspond to boundaries shared between inter-variant grain pairs [48]. With increasing thickness reduction the LAGB population is observed to increase.

Analysis of the inter-variant boundary population shows that the parent $\gamma$ phase shares the ShojiNishiyama (S-N) orientation relationship (OR, $\left.(111)_{\gamma}\left\|(0001)_{\varepsilon},[1 \overline{1} 0]_{\gamma}\right\|[11 \overline{2} 0]_{\varepsilon}\right)$ with $\varepsilon$-martensite $[49$, 50] and the Kurdjumov-Sachs (K-S OR, $(111)_{\gamma}\left\|(110)_{\alpha^{\prime}},[\overline{1} 10]_{\gamma}\right\|[\overline{1} 11]_{\alpha^{\prime}}$ ) with $\alpha^{\prime}$-martensite [51]. Alternatively, the transformation from $\varepsilon$ to $\alpha^{\prime}$-martensite phases follows the Burgers OR $\left((111)_{\varepsilon} \|\right.$ $\left.(0001)_{\alpha^{\prime}},[1 \overline{1} 1]_{\varepsilon} \|[11 \overline{2} 0]_{\alpha^{\prime}}\right][49,52]$. The Burgers OR is also widely reported during the $\beta$ (bcc) to $\alpha(\mathrm{hcp})$ phase transformation process in titanium alloys. Table 4 in Ref. [48] presents the theoretical misorientation axis-angle pairs of the $\beta$ phase when the transformation occurs from $\alpha$ to $\beta$ via Burgers OR. It follows that the misorientation axis-angle pairs observed in $\alpha^{\prime}$-martensite (Fig. $3 \mathrm{c}$ ) are analogous to those reported in Table 4 in Ref. [48].

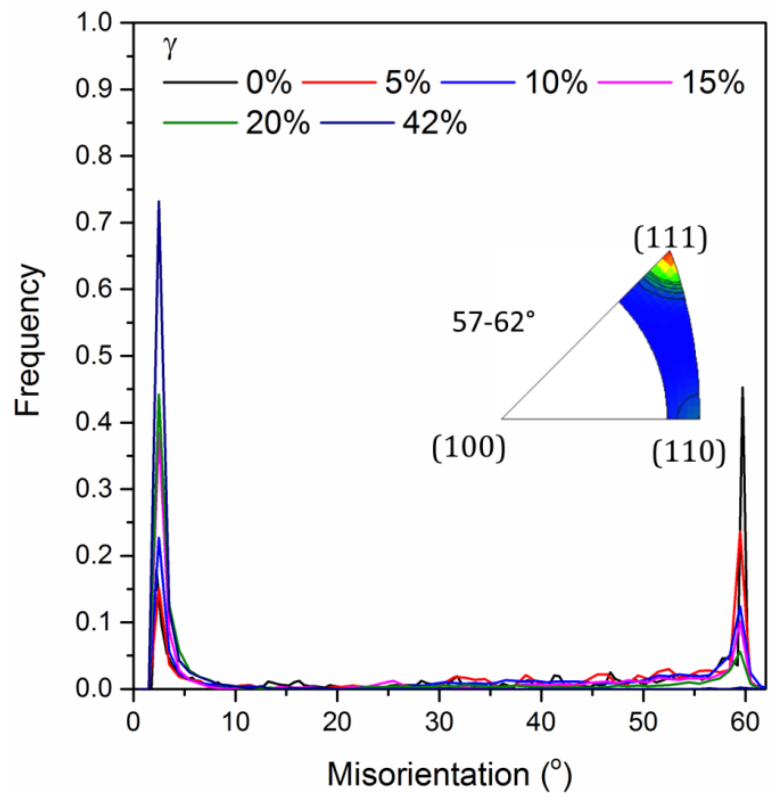

(a)

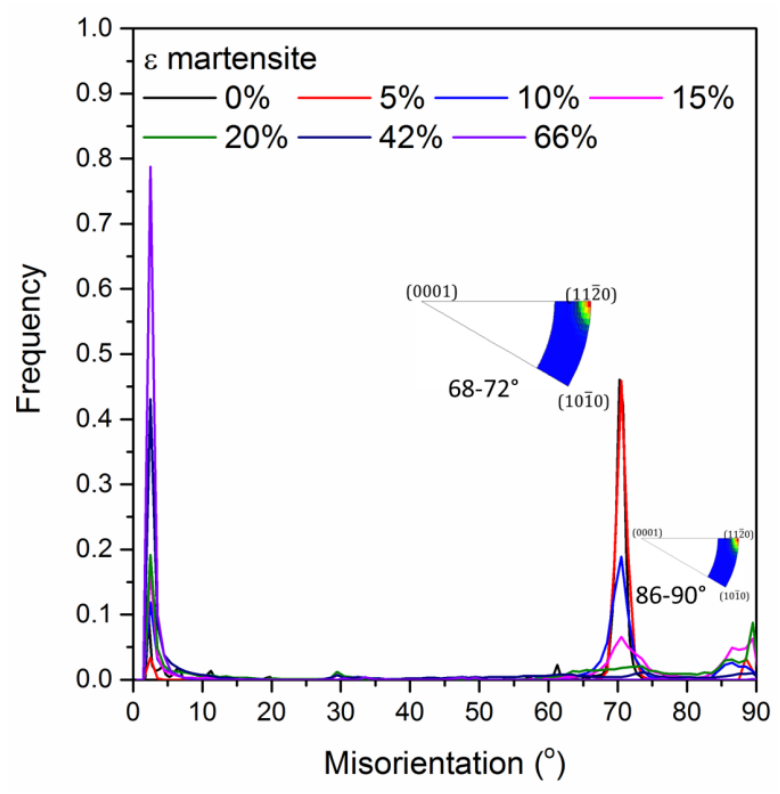

(b) 


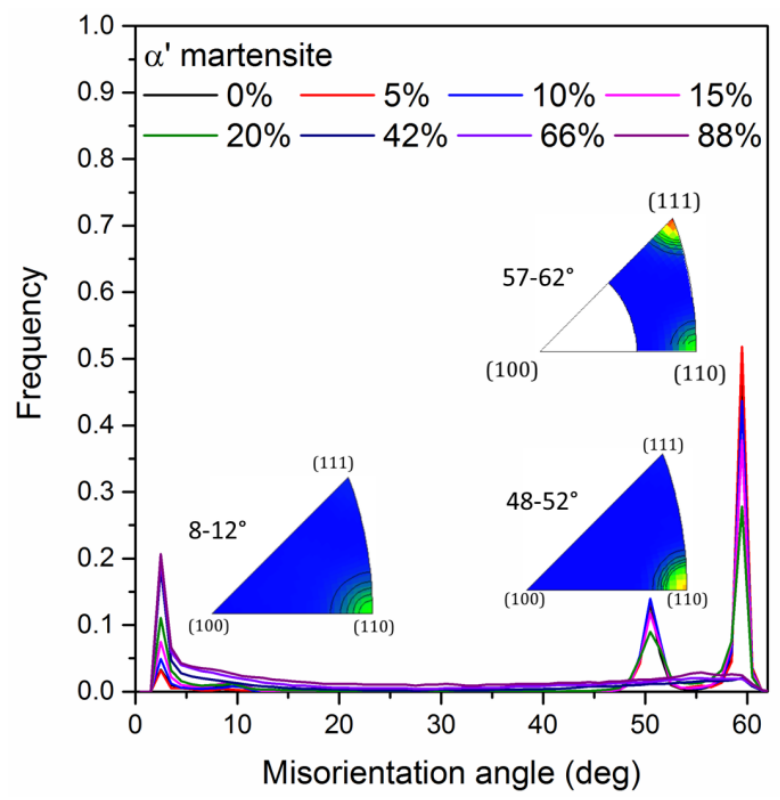

(c)

Figure 3: Misorientation angle distributions of (a) $\gamma$, (b) $\varepsilon$-martensite and (c) $\alpha^{\prime}$-martensite with thickness reduction up to $88 \%$.

In Fig. 4, representative bright-field micrographs highlight the microstructure evolution with increasing thickness reduction. Coarse $\varepsilon$-martensite plates after hot-rolling and $15 \%$ thickness reduction share the S-N OR with their parent $\gamma$ grains (Figs. 4a and 4b). The substructure of deformation-induced $\alpha^{\prime}$-martensite has been observed to contain dislocations which are shown in Fig. $4 \mathrm{~b}$ and supplementary Fig. S2a. Similar dislocation substructures in $\alpha^{\prime}$-martensite has been observed in an Fe-17Mn-0.05C steel after uniaxial tension to $15 \%$ engineering strain [44]. At $42 \%$ thickness reduction, both $\varepsilon$ and deformation-induced $\alpha^{\prime}$-martensite are seen (Fig. 4c). Thickness reduction to 66\% and 88\% (Figs. 4d and $4 \mathrm{e}$ ) results in fine, elongated $\varepsilon$-martensite grains interspersed along $\alpha^{\prime}$-martensite boundaries (for darkfield images refer to supplementary section Figs. S3a and S3b). 


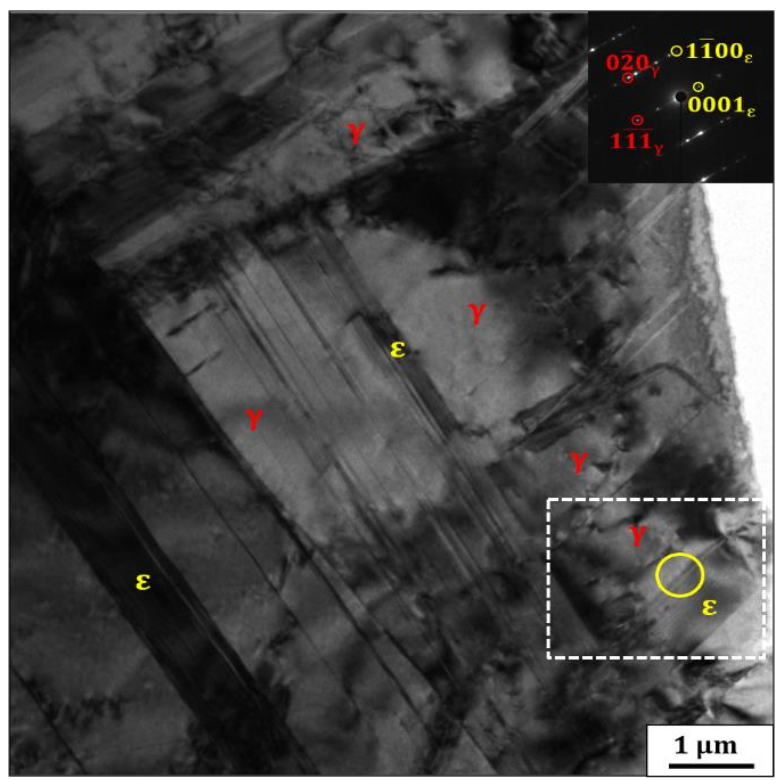

(a)

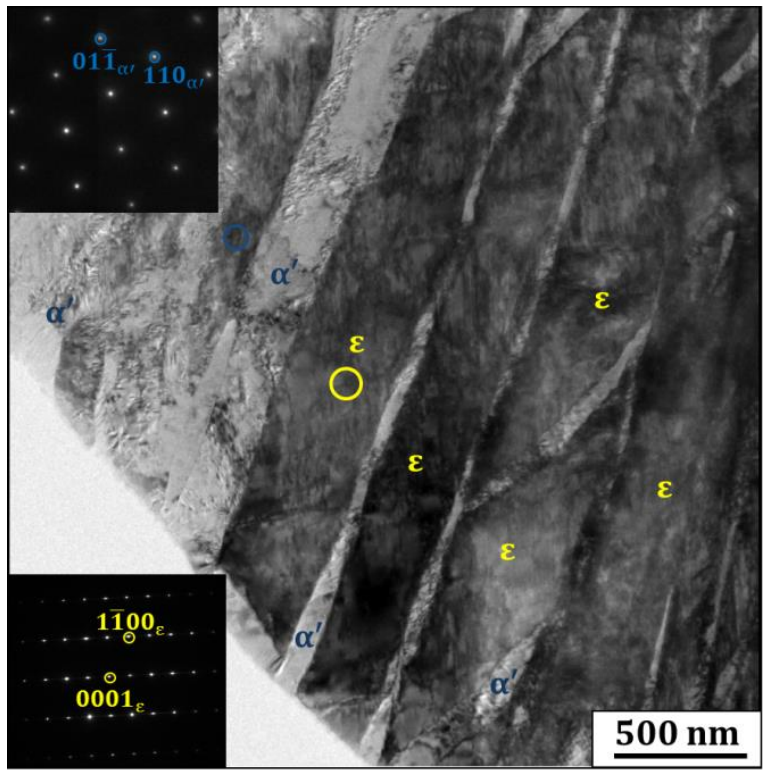

(c)

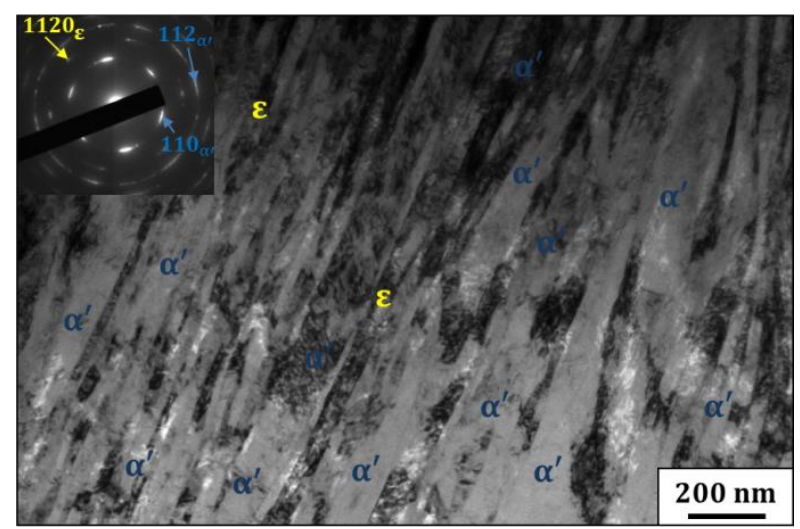

(e)

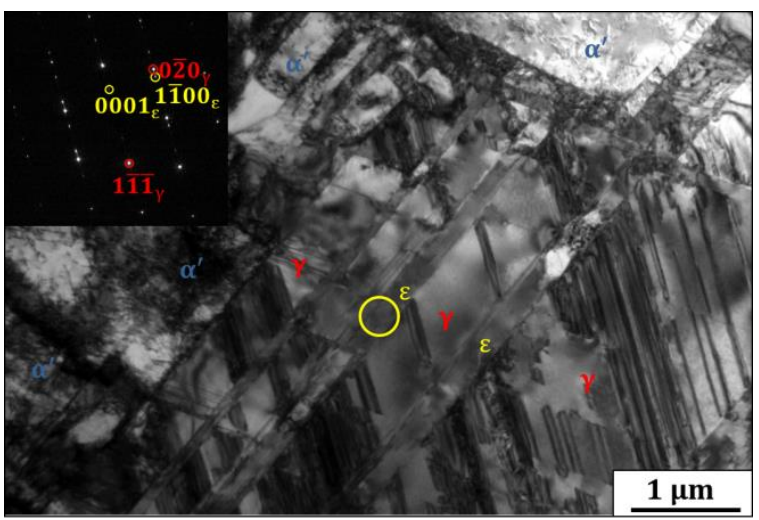

(b)

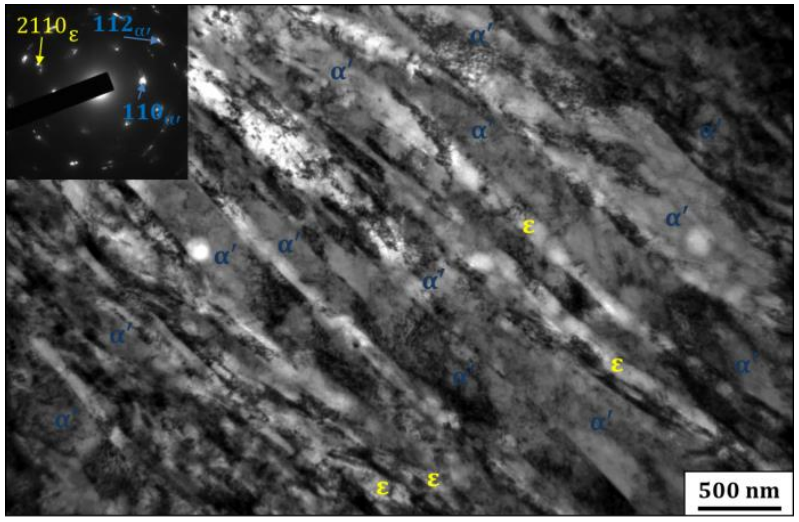

(d)

Figure 4: Representative (a-e) bright-field transmission electron micrographs after (a) hot-rolling and thickness reduction to (b) 15\%, (c) 42\%, (d) $66 \%$ and (e) $88 \%$. The inset diffraction patterns in Figs. $4 \mathrm{a}-4 \mathrm{e}$ are from the regions demarcated by yellow circles or the complete area of interest. Zone 
axes are $[101]_{\gamma^{\prime}},[11 \overline{2} 0]_{\varepsilon}$ in Figs. $4 \mathrm{a}$ and $4 \mathrm{~b}$ and $[1 \overline{1} \overline{1}]_{\alpha^{\prime}},[11 \overline{2} 0]_{\varepsilon}$ in Fig. $4 \mathrm{c}$.

\subsection{Nucleation of deformation-induced $\varepsilon$-martensite and its interaction with the $\gamma$ phase}

Fig. $5 \mathrm{a}$ is a bright-field micrograph after 5\% thickness reduction showing the nucleation of fine, deformation-induced $\varepsilon$-martensite laths following the S-N OR (inset diffraction pattern). The dark-field image in Fig. 5 b shows a $3 \pm 1 \mathrm{~nm}$ wide deformation-induced $\varepsilon$-martensite lath alongside a $19 \pm 3 \mathrm{~nm}$ wide deformation-induced $\varepsilon$-martensite. Note here the attenuation in intensity in the dark-field image (Fig. 5b) on moving along the $3 \mathrm{~nm}$ wide deformation-induced $\varepsilon$-martensite lath. HAADF STEM micrographs from regions: (1) along an edge very near the tip and (2) within the $\varepsilon$-martensite lath are given in Figs. $5 c$ and 5 d, respectively. The edge region near the tip comprises the $\gamma$ phase with $\gamma$-ISFs ${ }^{1}$ and a 4 layer nucleus of $\varepsilon$-martensite (Fig. 5 c). Within the $\varepsilon$-martensite lath, a thin layer of untransformed $\gamma$ is also seen (Fig. 5d). The interface between the $\gamma$ and $\varepsilon$-martensite phases along the $[0002]_{\varepsilon}$ direction is smooth with a one-to-one congruence between the fcc and hcp atoms.

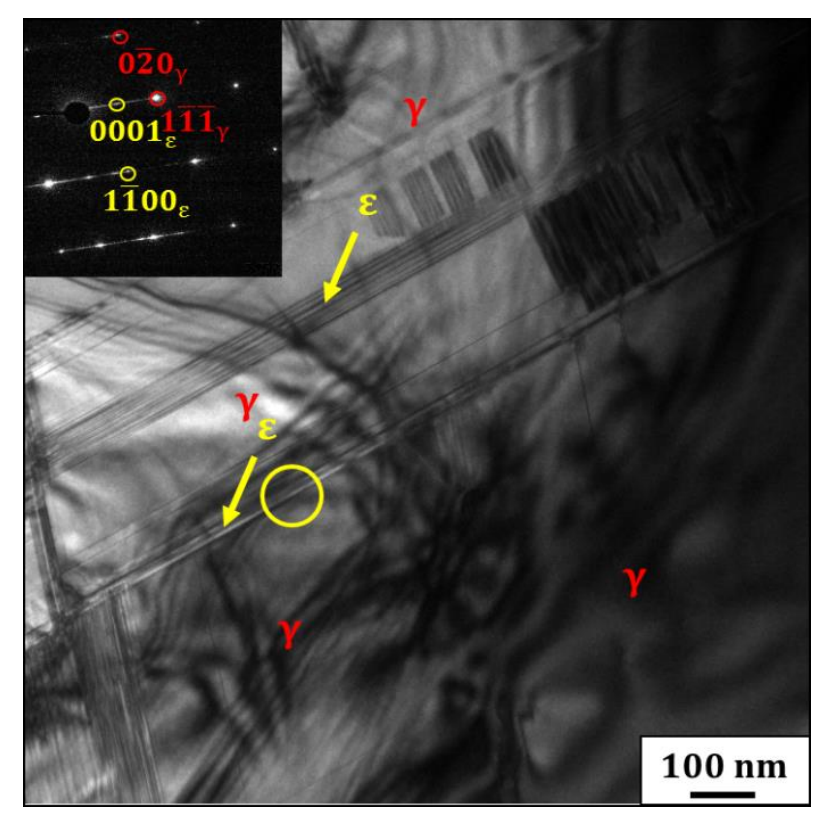

(a)

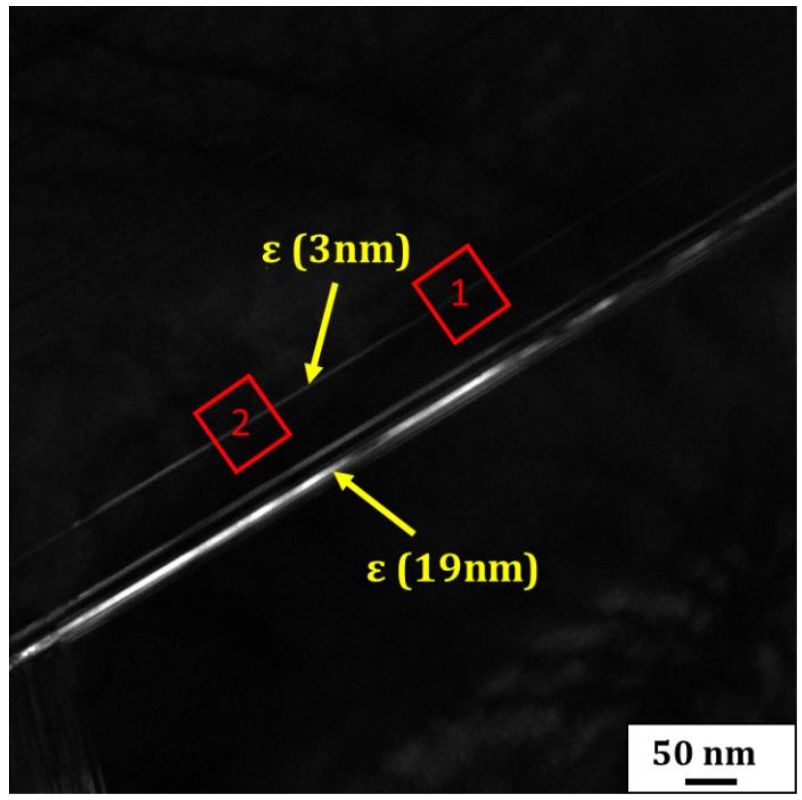

(b)

\footnotetext{
1 The character of stacking faults in the $\gamma$ phase is summarised briefly as follows. The motion of a Shockley partial on a close-packed plane produces an intrinsic stacking fault $(\gamma$-ISF) with the atomic arrangement ABCA|CABC whereas the motion on two consecutive close packed planes creates an extrinsic stacking fault ( $\gamma$-ESF) with the atomic arrangement $\mathrm{ABCAB}|\mathrm{A}| \mathrm{CAB}$. An alternate explanation of $\gamma$-ISFs and $\gamma$-ESFs in the $\gamma$ phase is the removal and addition of an extra atomic layer, respectively.
} 


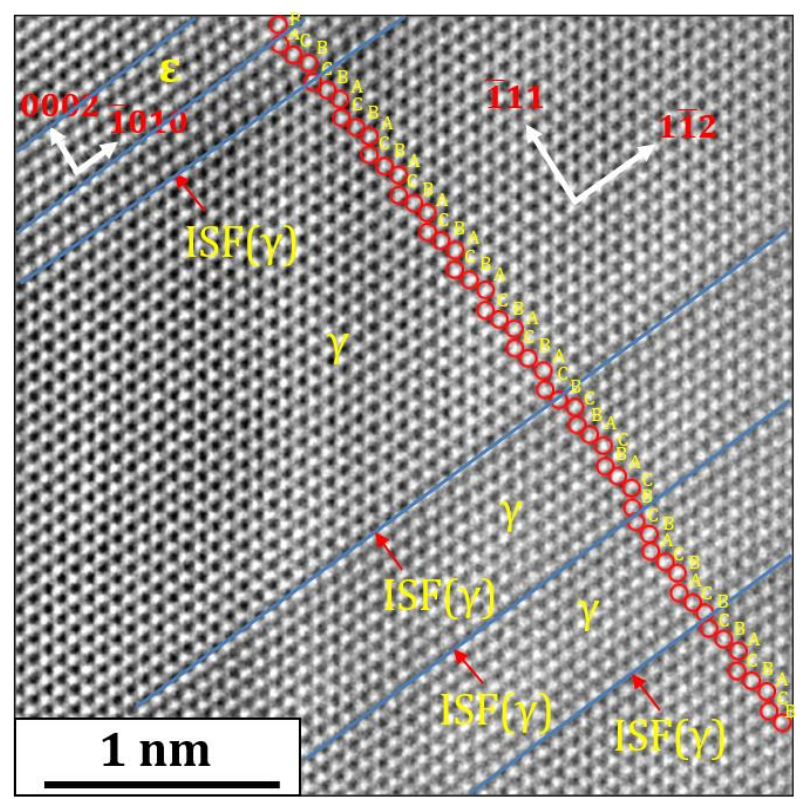

(c)

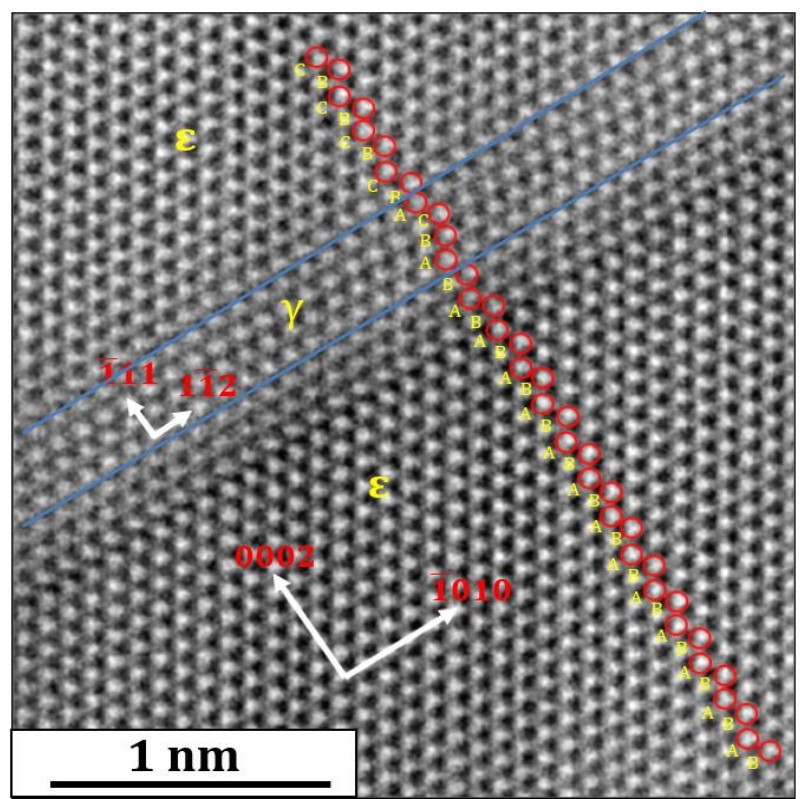

(d)

Figure 5: Representative (a) bright-field, (b) dark-field TEM micrographs and (c, d) HAADF STEM images after 5\% thickness reduction. Figs. $5 \mathrm{c}$ and $5 \mathrm{~d}$ are from regions (1) and (2) in Fig. 5b, respectively. In Figs. 5c and 5d, blue solid lines denote $\gamma$-stacking fault planes. The inset diffraction pattern in Fig. 5 a is from the region demarcated by yellow circle. Zone axes are $[101]_{\gamma}$ and $[11 \overline{2} 0]_{\varepsilon}$.

Figs. 6a, $6 \mathrm{~b}$ are bright-field STEM micrographs of deformation-induced $\varepsilon$-martensite laths at $10 \%$ thickness reduction. HAADF STEM micrographs of the regions (1), (2) and (3) are presented in Figs. 6c$6 e$, respectively, to highlight the interface between and the deformation-induced $\varepsilon$-martensite laths and their internal structure. In Fig. 6c, the interaction region shown using dashed blue lines depicts a distorted $\gamma$ lattice undergone a shear of 0.09 , which in turn causes a localised distortion when transitioning from the fcc to hcp lattices along the $[10 \overline{1} 0]_{\varepsilon}$ direction. On the other hand, in Fig. $6 \mathrm{~d}$ the interface between the $\gamma$ and $\varepsilon$-martensite is smooth and without ledges along the $[0002]_{\varepsilon}$ direction. The tips of $\varepsilon$-martensite laths terminate in a Shockley partial dislocation (Fig. 6e). It is noted that the 3-6 nm thick $\varepsilon$-martensite laths present in the samples deformed to 5 and $10 \%$ thickness reductions (Figs. $5 \mathrm{~b}, 6 \mathrm{~b}$ ) do not contain stacking faults and are much finer than those observed in the hot-rolled sample. This indicates that these fine $\varepsilon$-martensite laths are newly formed deformation-induced $\varepsilon$-martensite. 


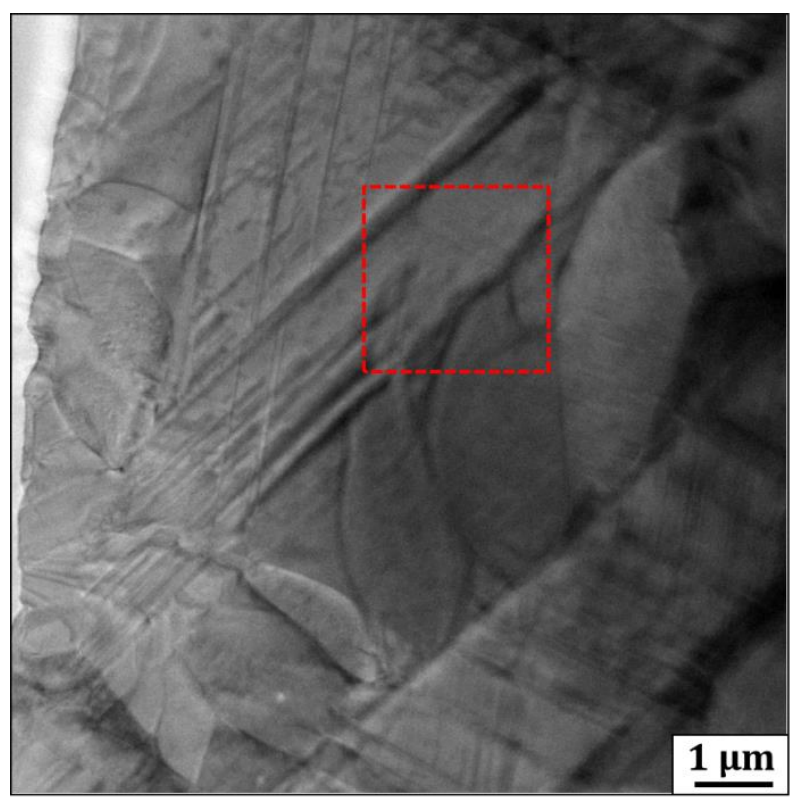

(a)

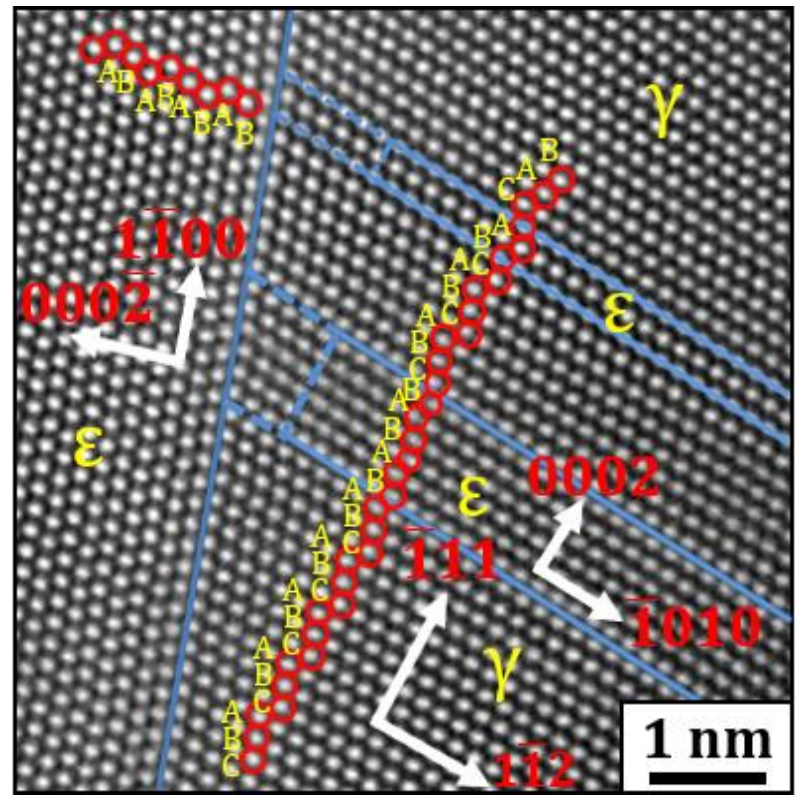

(c)

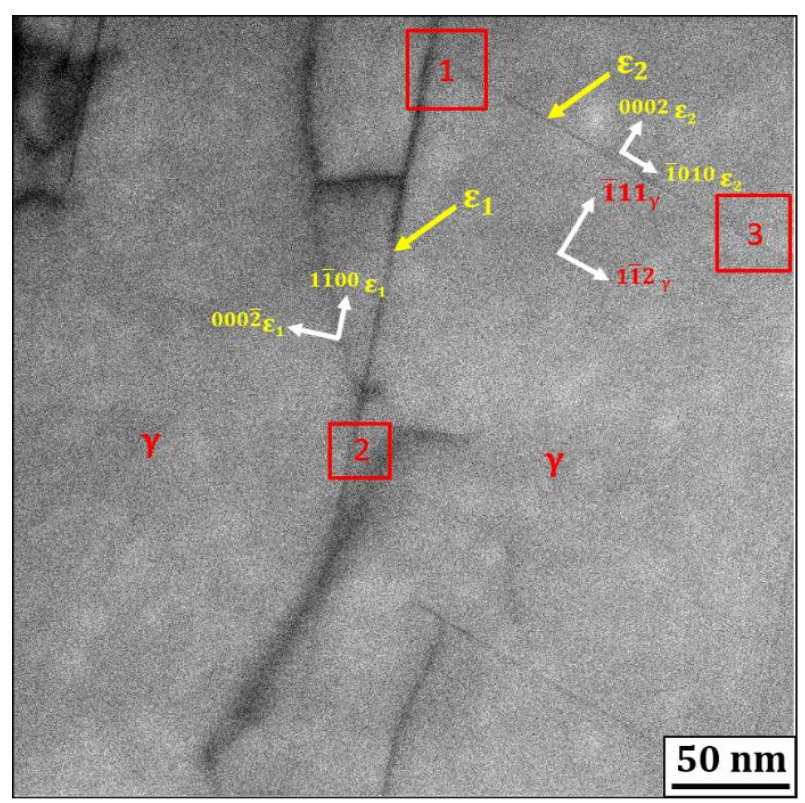

(b)

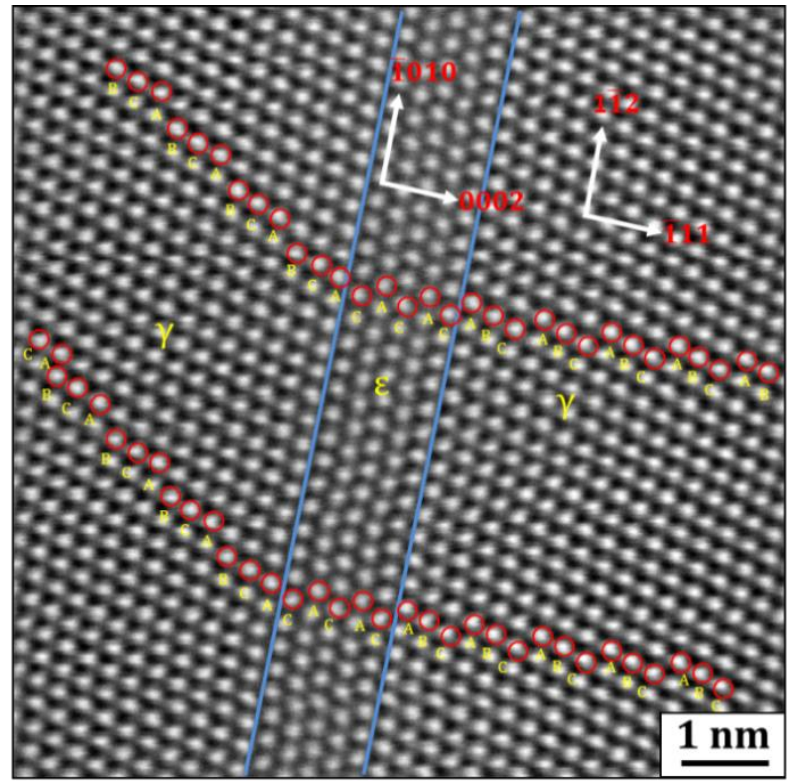

(d) 


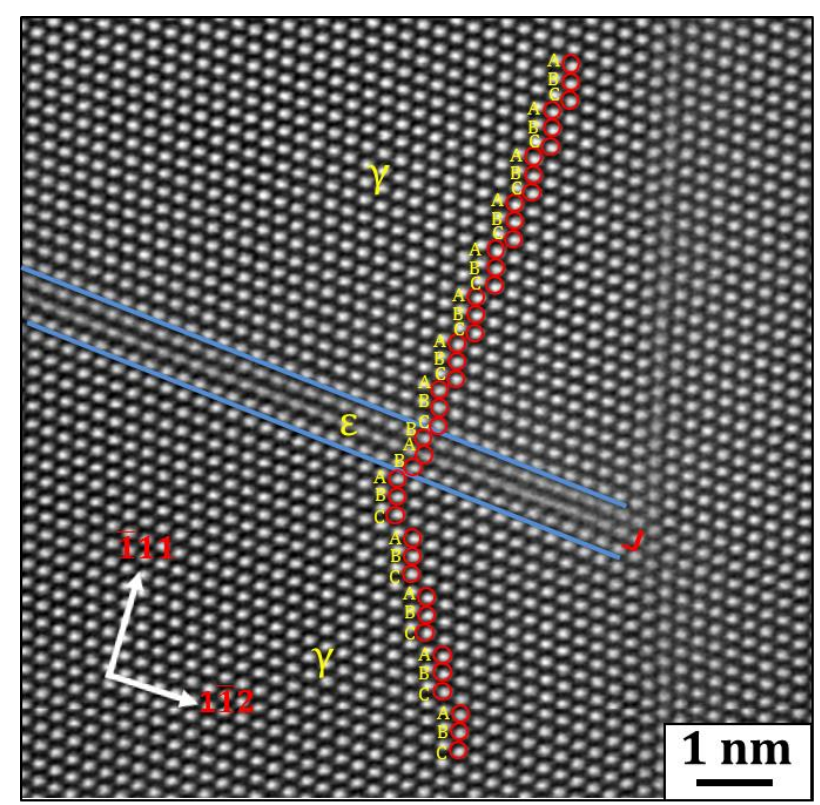

(e)

Figure 6: Representative (a, b) bright-field STEM micrographs and (c-e) HAADF STEM micrographs after $10 \%$ thickness reduction. Fig. $6 \mathrm{~b}$ is a magnified view of the region denoted by red dashed square in Fig. 6a. Figs. 6c-6e are from the regions (1) to (3) in Fig. 6b, respectively. In Figs. 6c-6e, blue dashed lines denote the $\gamma / \varepsilon$-martensite interface while the Shockley partial dislocations are given by the symbol "لـ".

\subsection{E-martensite: Deformation accommodation mechanisms and the character of stacking faults}

The following section details the deformation accommodation in $\varepsilon$-martensite as a combination of perfect and partial basal slip, pyramidal slip along with $\{10 \overline{1} 2\}\langle\overline{1} 011\rangle_{\varepsilon}$ extension twinning. In this regard, of the prevalence of partial basal slip leads to the formation of $I_{1}$ and $I_{2}$-type $\varepsilon$-ISFs.

Fig. 7a is a magnified, dark-field micrograph of an $\varepsilon$-martensite plate formed on quenching after hot-rolling and located within the dashed white rectangle shown in Fig. 4a. The HAADF STEM micrograph of the interface between $\gamma$ and $\varepsilon$-martensite (see the solid red square in Fig. 7a) is given in Fig. 7b. The micrographs reveal that while $\gamma$-ISFs are formed within the $\gamma$ phase during hot-rolling, the $\varepsilon$-martensite plate formed on quenching after hot-rolling does not contain any faults. A representative distribution of relatively fine and coarse deformation-induced $\varepsilon$-martensite laths after $5 \%$ thickness reduction is shown using a dark-field micrograph from a $(0001)_{\varepsilon}$ diffraction spot in Fig. 7c. The HAADF STEM image of a 65 nm wide $\varepsilon$-martensite lath (see the solid red square in Fig. $7 \mathrm{c}$ ) shown in Fig. $7 d$ returns an $\mathrm{I}_{1}$-type $\varepsilon$-ISF. 


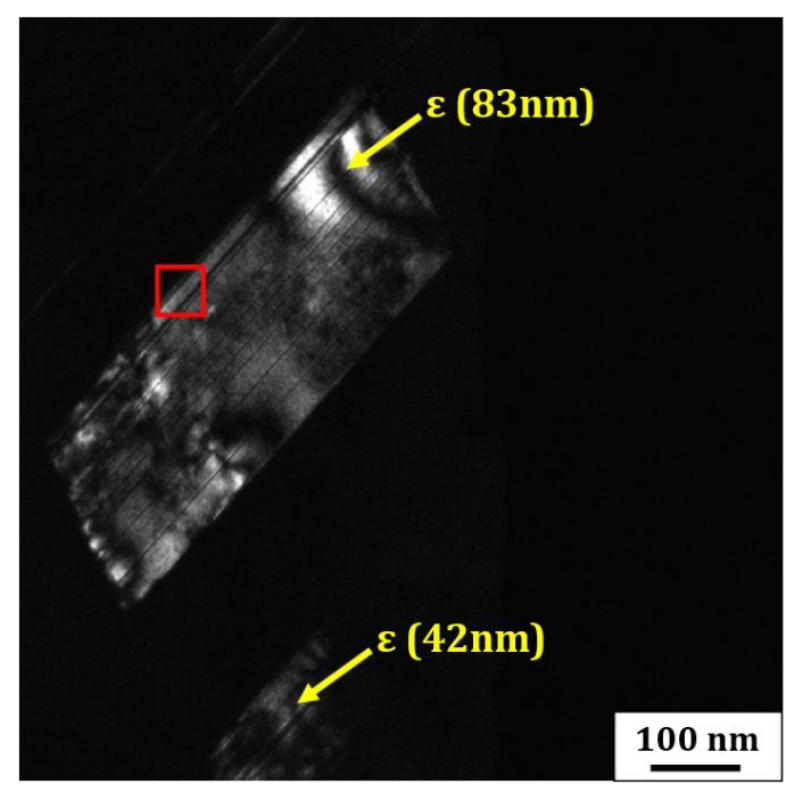

(a)

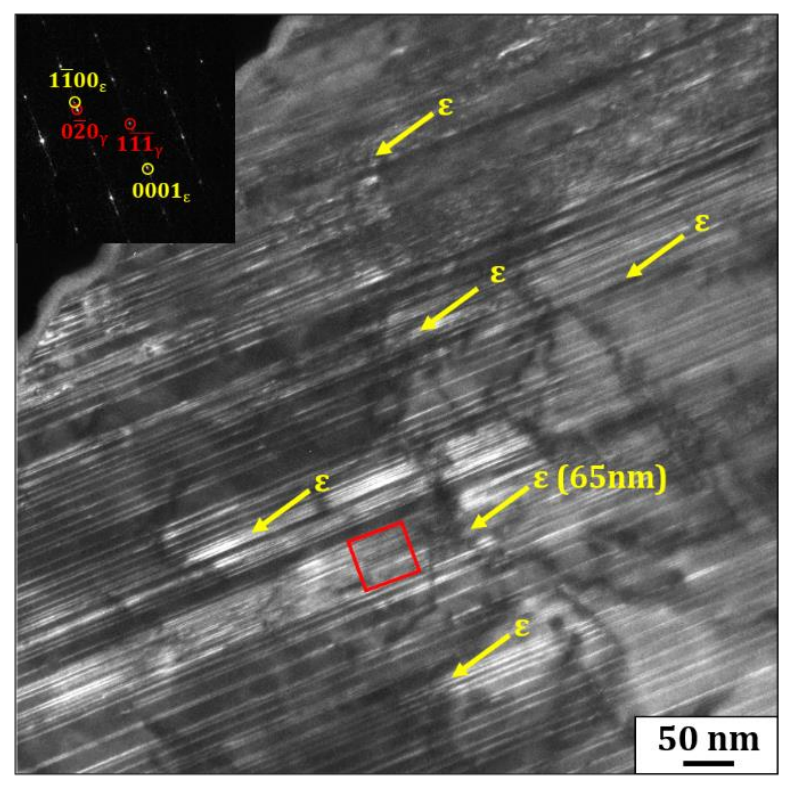

(c)

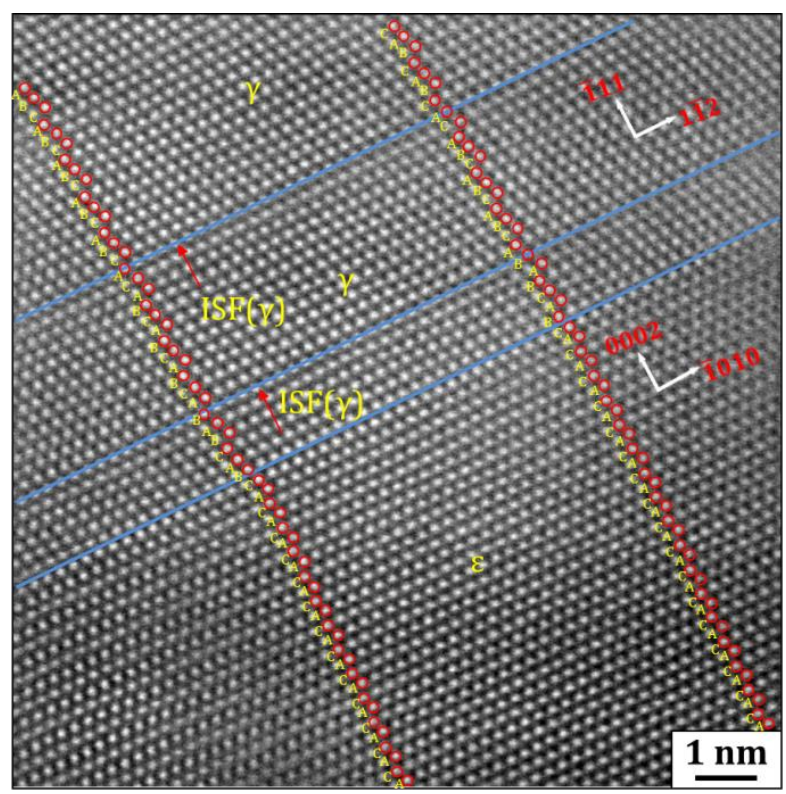

(b)

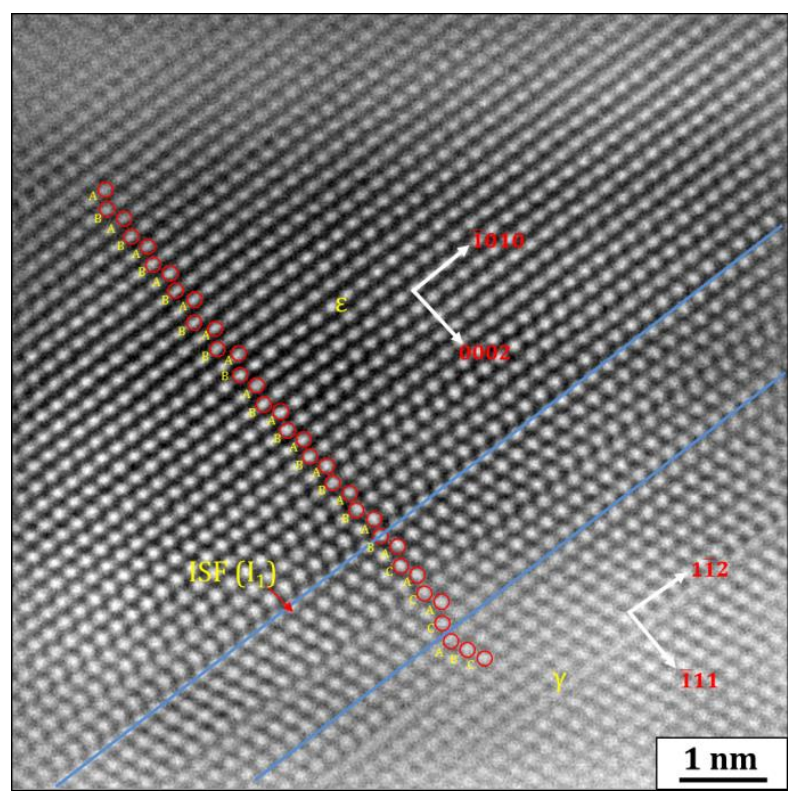

(d)

Figure 7: Representative (a, c) dark-field micrographs and (b, d) HAADF STEM micrographs after (a, b) hot-rolling and (c, d) thickness reduction to 5\%. The inset diffraction pattern in Figs. $7 \mathrm{c}$ is from the region demarcated by red square. Zone axes are $[101]_{\gamma},[11 \overline{2} 0]_{\varepsilon}$ in Figs. $7 \mathrm{c}$.

Figs. $8 \mathrm{a}$ and $8 \mathrm{~b}$ are the representative bright and dark-field micrographs, respectively after $10 \%$ thickness reduction. The dark-field image was from the highest intensity spot in the inset diffraction pattern of Fig. 8a taken from the region highlighted by the yellow circle. A representative HAADF STEM micrograph of the $20 \mathrm{~nm}$ wide $\varepsilon$-martensite lath shows an $\mathrm{I}_{2}$-type $\varepsilon$-ISF highlighted by the blue lines in Fig. 8c. Fig. 8d shows multiple $I_{1}$-type $\varepsilon$-ISFs highlighted by blue lines on parallel $(0002)_{\varepsilon}$ planes within a $64 \mathrm{~nm}$ wide $\varepsilon$-martensite lath. $\varepsilon$-ISFs have also been identified in samples after $15 \%$ thickness reduction in dark-field micrographs (presented in supplementary Fig. S4a) obtained under two beam conditions using $\mathrm{g}=[01 \overline{1} 1]_{\varepsilon}[53]$, by employing the procedures outlined in Ref. [54] which is presented in 
supplementary Fig. S4a. In $\varepsilon$-martensite, $\mathrm{I}_{1}$ and $\mathrm{I}_{2}$-type $\varepsilon$-ISFs are created by the motion of Shockley partial dislocations that form by the dissociation of $\frac{a}{3}[2 \overline{1} \overline{1} 0]_{\varepsilon}$ perfect dislocations by the reaction:

$$
\frac{\mathrm{a}}{3}[2 \overline{1} \overline{1} 0]_{\varepsilon} \rightarrow \frac{\mathrm{a}}{3}[10 \overline{1} 0]_{\varepsilon}+\frac{\mathrm{a}}{3}[1 \overline{1} 00]_{\varepsilon}
$$

A representative HAADF STEM micrograph of a $223 \mathrm{~nm}$ wide $\varepsilon$-martensite plate after $42 \%$ thickness reduction (taken from the yellow circular region in Fig. 4c) shown in Fig. 8e returns only $\mathrm{I}_{1}-$ type $\varepsilon$-ISFs highlighted by blue lines whose widths coarsen by the motion of Shockley partial dislocations on the basal planes. In this micrograph, it is also clearly seen that Shockley partial dislocations tend to blur the atomic layers in their immediate vicinity due to the strain fields associated with their formation that cause a small localised shift in atomic positions; thereby obstructing electron channelling along atomic columns and reducing the overall image contrast. Fig. $8 \mathrm{f}$ shows an evidence of dislocation activity in the pyramidal plane of $\varepsilon$-martensite after $15 \%$ thickness reduction in the form of dislocations tangles (highlighted by black arrows in the inset) and stacking faults (highlighted by black arrows in the middle of the micrograph). Similar high activity of pyramidal dislocations was reported in Mg-3Y (wt. \%) alloys after slight plastic deformation (3\% engineering strain) [55]. The possibility of $\{10 \overline{1} 1\}_{\varepsilon}$ pyramidal slip in Mg has been also shown by molecular dynamics simulations [56].

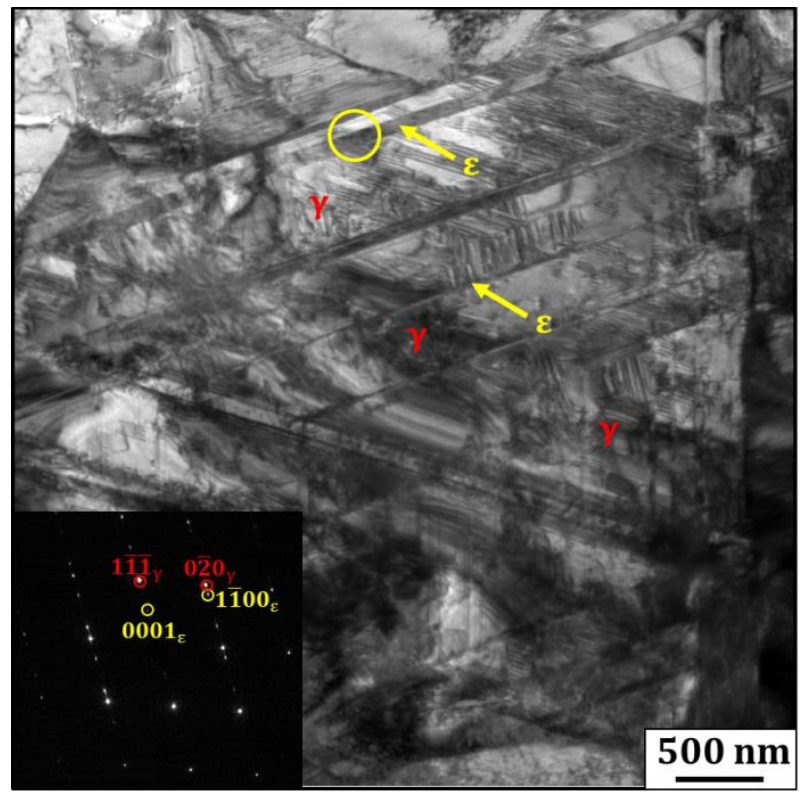

(a)

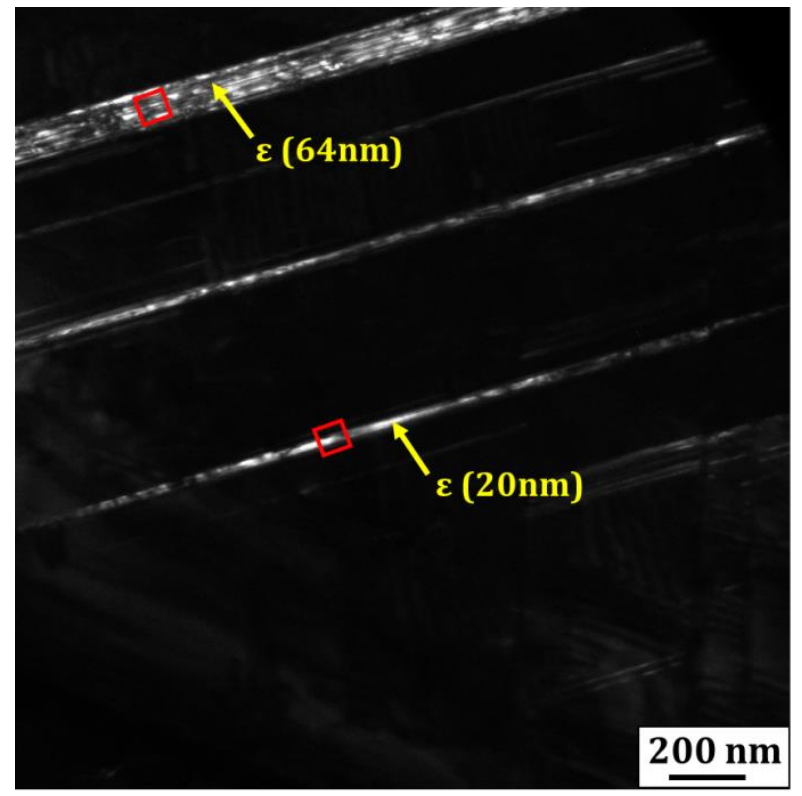

(b) 


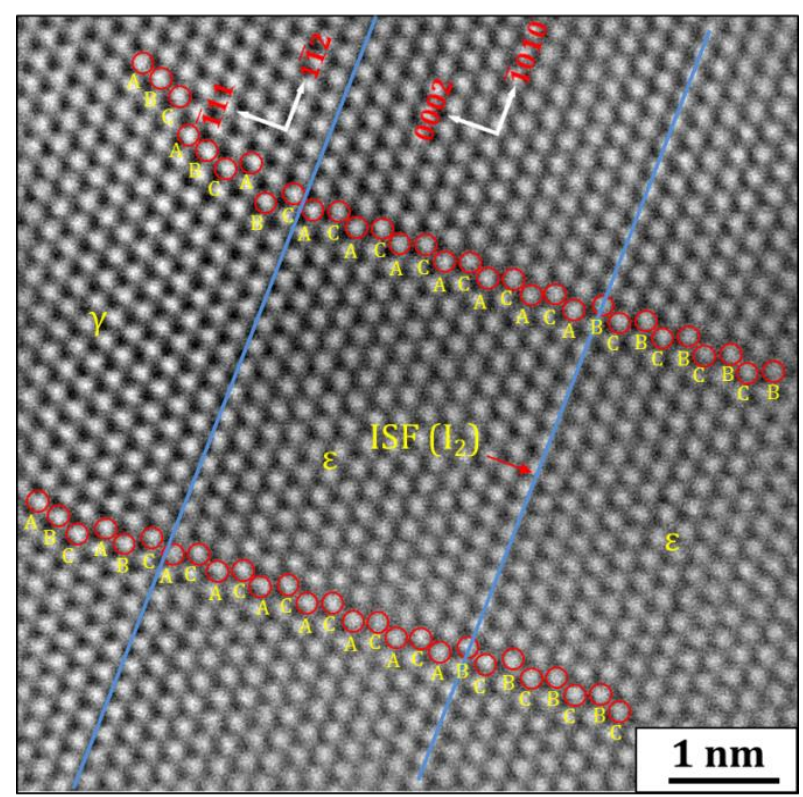

(c)

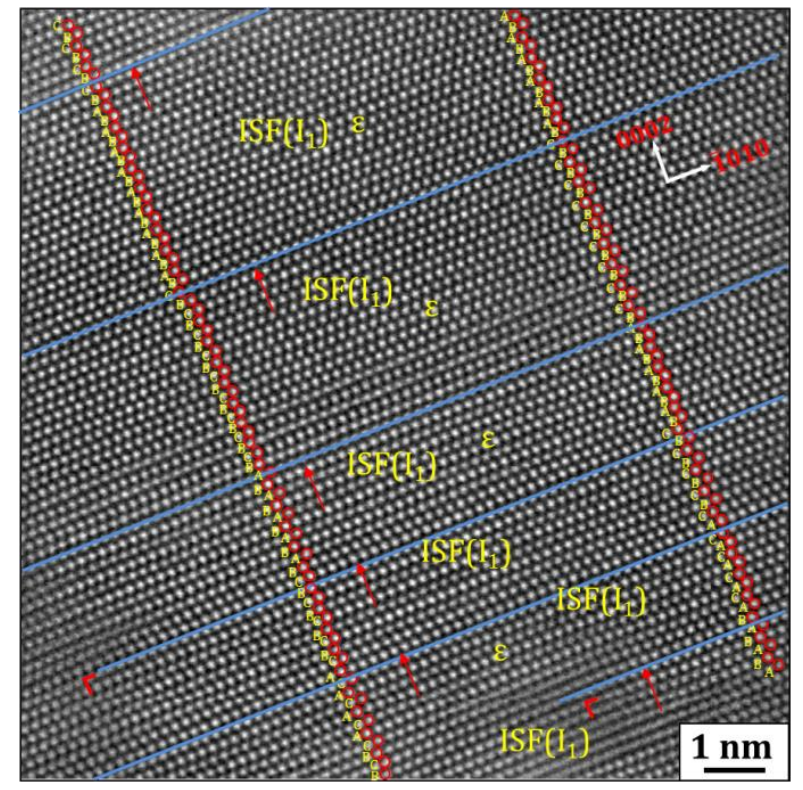

(e)

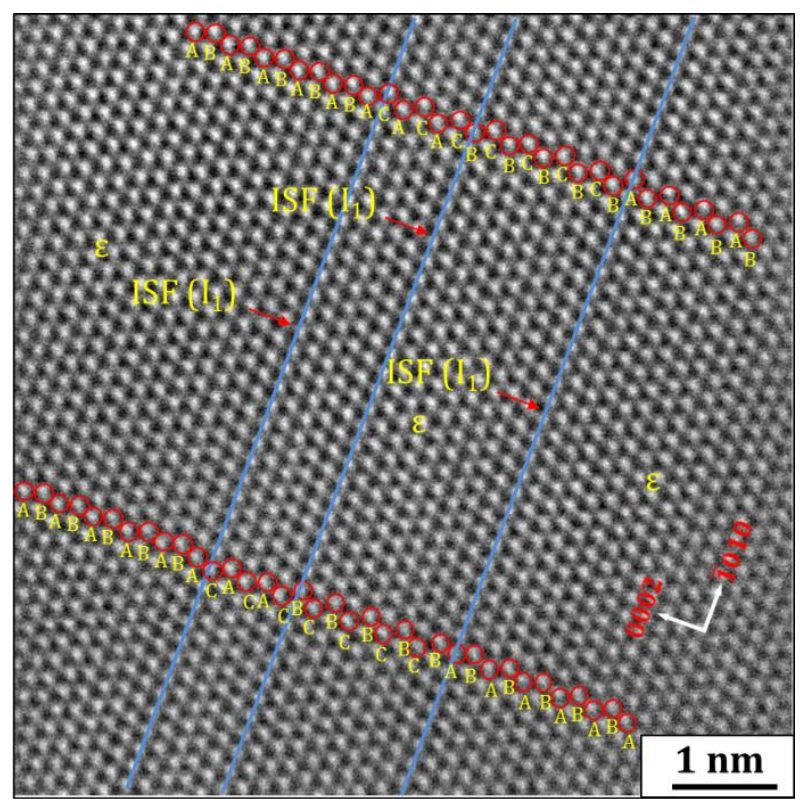

(d)

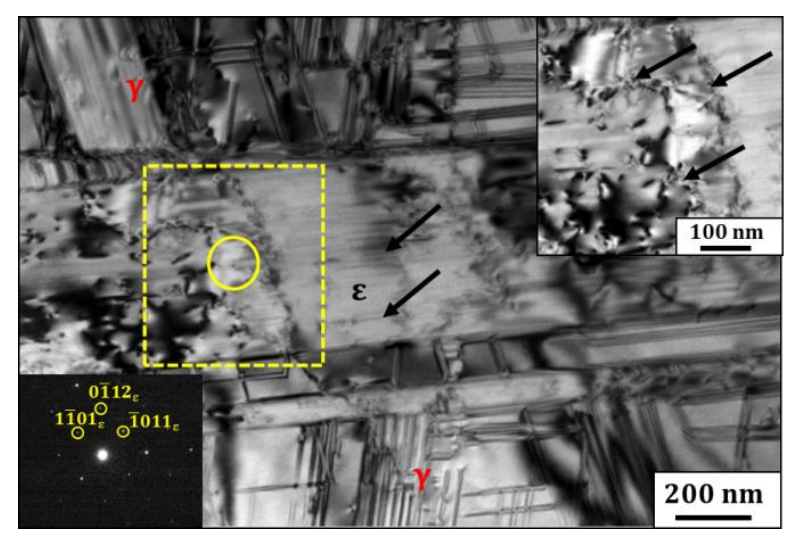

(f)

Figure 8: Representative (a, f) bright-field micrographs, (b) dark-field micrograph, (c, d, e) HAADF STEM micrographs after thickness reduction to (a-d) $10 \%$, (e) $42 \%$ and (f) $15 \%$. Shockley partial dislocations are given by the symbol "ل" in Fig. 8e. The inset diffraction patterns in Figs. 8a and 8f are from the regions demarcated by yellow circles. Zone axes are $[101]_{\gamma},[11 \overline{2} 0]_{\varepsilon}$ in Fig. 8a and $[01 \overline{1} 1]_{\varepsilon}$ in Fig. 8f.

\section{Discussion}

Based on the results in Section 3, a rough schematic of the deformation accommodation and transformation behaviours with increasing thickness reduction is provided in Fig. 9. Upon quenching after hot-rolling (step 1), the microstructure comprises a $\gamma$ phase with stacking faults (in purple) and annealing twins (in yellow). Parallel and intersecting $\varepsilon$-martensite plates and $\alpha^{\prime}$-martensite grains that 
form upon quenching are present within individual $\gamma$ grains. However, this is not shown in the schematic in Fig. 9 as the discussion here is focused on the deformation and subsequent transformation behaviour of $\gamma$ and does not include the deformation of $\varepsilon$ and $\alpha^{\prime}$-martensite formed upon quenching after annealing. Up to $\sim 10 \%$ thickness reduction (step 2), deformation accommodation in $\gamma$ takes place by partial slip which leads to the formation of $\gamma$-ISFs and transformation to deformation induced $\varepsilon$-martensite. Deformation-induced $\varepsilon$-martensite laths appear either alongside $\varepsilon$-martensite plates or in isolation and at $\gamma$ annealing twins. Concurrently, $\mathrm{I}_{2} \varepsilon$-ISFs (in orange) forms in relatively fine $\varepsilon$-martensite laths and $\mathrm{I}_{1} \varepsilon$ ISFs (in brown) forms in relatively coarse $\varepsilon$-martensite laths.

Up to $\sim 20 \%$ thickness reduction (step 3 ), $I_{2}$-type $\varepsilon$-ISFs transition to $I_{1}$-type $\varepsilon$-ISFs in $\varepsilon$ martensite. Concomitantly, $\alpha^{\prime}$-martensite forms at the intersections of $\varepsilon$-martensite plates/laths, within $\varepsilon^{-}$ martensite plates/laths and also in the $\gamma$ matrix. The formation of $\{10 \overline{1} 2\}\langle\overline{1} 011\rangle_{\varepsilon}$ extension twins (in fuschia) also occurs in $\varepsilon$-martensite. Operation of partial slip leading to the formation of $\gamma$-ISFs (Fig. S3b), also continues at this stage of deformation. However, the formation of $\varepsilon$-martensite in $\gamma$ and $\alpha^{\prime}$-martensite in $\varepsilon$-martensite are becoming the dominant mechanisms.

Thickness reduction up to $\sim 42 \%$ (step 4) results in blocky $\varepsilon$-martensite morphology and elongated, fragmented $\alpha^{\prime}$-martensite morphology. Increasing the thickness reduction whereas after thickness reduction to $66 \%$ (step 5) leads to the further elongation of $\alpha^{\prime}$-martensite. The change in $\varepsilon$ martensite morphology from lath/plate through blocky to elongated types is explained by the gradual transformation of $\gamma$ to $\varepsilon$ and the partial transformation of $\varepsilon$ to $\alpha^{\prime}$-martensite with larger thickness reduction. At the highest thickness reduction of this study (88\%, step 6), the microstructure is dominated by the $\alpha^{\prime}$-martensite with only trace fractions of $\gamma$ and $\varepsilon$-martensite remaining. Here, $\alpha^{\prime}$-martensite accommodates deformation up to $88 \%$ thickness reduction via slip as evidenced by the increase in LAGB fraction (Fig. 3c) and formation of local macroscopic shear bands (Fig. 2h).

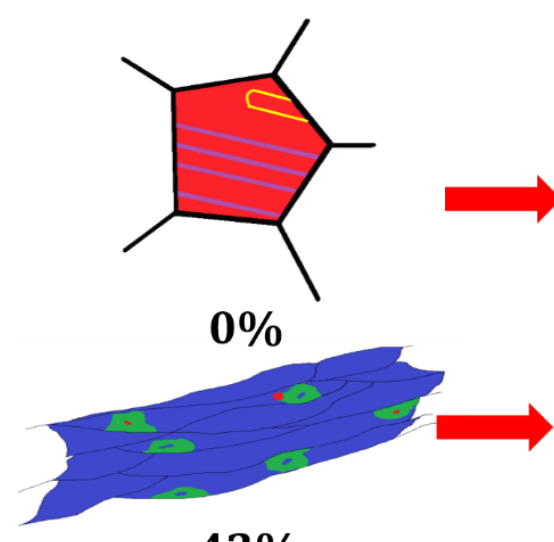

$42 \%$

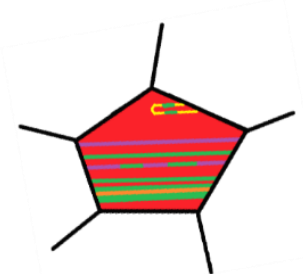

$5-10 \%$

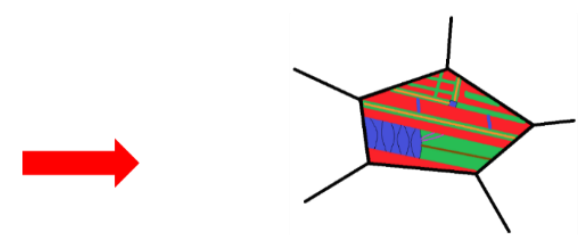

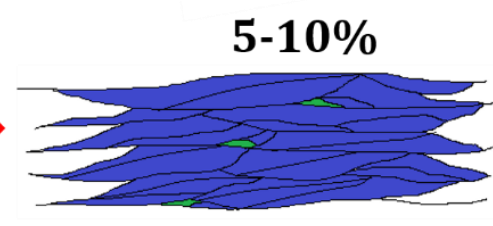

$66 \%$
$10-20 \%$

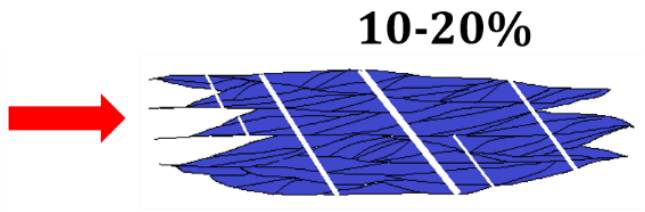

$88 \%$

Figure 9: Schematic of deformation accommodation and transformation behaviour with thickness reduction up to $88 \%$. Red $=\gamma$, green $=\varepsilon$-martensite, blue $=\alpha^{\prime}$-martensite. Intrinsic stacking faults in $\gamma$ are shown in purple while $I_{2}$ and $I_{1}$ faults in $\varepsilon$-martensite are shown in orange and brown, respectively. Annealing twins in $\gamma$ and $\{10 \overline{1} 2\}\langle\overline{1} 011\rangle_{\varepsilon}$ extension twins in $\varepsilon$-martensite are shown in yellow and fuschia, respectively. 


\subsection{Nucleation of deformation-induced $\varepsilon$-martensite and its subsequent coarsening via coalescence}

The results shown in Sections 3.2 and 3.3 do not support the earlier suggestion of $\varepsilon$-martensite comprising a bundle of $\gamma$ stacking faults [57] as: (i) EBSD clearly indexed $\varepsilon$-martensite as a distinct hcp phase, and the HAADF STEM images show (ii) a distinct hcp stacking sequence and (iii) a clear transition from $\gamma$ to $\varepsilon$ crystal lattices.

The nucleation of deformation-induced $\varepsilon$-martensite can be deduced from Figs. $5 \mathrm{c}$ and $5 \mathrm{~d}$ at $5 \%$ thickness reduction. In agreement with previous observations [58-61], $\gamma$-ISFs in the $\gamma$ phase nucleate $\varepsilon$ martensite; which in turn coarsens laterally in the form of fine deformation-induced laths. The presence of an untransformed $\gamma$ region in Fig. 5d indicates incomplete lateral coarsening. Fujita and Ueda [60] made a similar observation and proposed a mechanism to explain this by suggesting that stacking faults form irregularly on $(111)_{\gamma}$ plane assisted by the motion of Shockley partials emitted from $\gamma$ grain boundaries; which coarsen laterally to nucleate deformation-induced $\varepsilon$-martensite. The width of the stacking faults increases due to the activation of more faults in nearby $(111)_{\gamma}$ planes; thus enhancing lateral coarsening as $\varepsilon$-martensite propagates within $\gamma$ grains [60].

Supplementary Fig. S5 shows a weak beam dark-field image (WBDF) of Shockley partial dislocations in $\gamma$ after 5\% thickness reduction. Fig. S5 shows the interaction of dislocations leading to a non-equilibrium partial spacing which prohibits the calculation of $\gamma$-SFE under the $5 \%$ thickness reduction. Alternatively, the $\gamma$-SFE in high Mn steels available in the literature have been listed in supplementary Table 1. It should be noted that the calculated $\gamma$-SFE $=14.5 \mathrm{~mJ} / \mathrm{m}^{2}$ [40] for the present steel favours the creation of $\gamma$-ISFs which in turn nucleates $\varepsilon$-martensite (supplementary Table 1 ). In the case of Fe-22Mn-3Al-3Si and Fe-25Mn-3Al-3Si steels, Pierce et al. [62] applied the WBDF method and estimated the $\gamma$-SFE in these steels as $15 \pm 3 \mathrm{~mJ} / \mathrm{m}^{2}$ and $21 \pm 3 \mathrm{~mJ} / \mathrm{m}^{2}$, respectively (supplementary Table 1). In agreement with the present results, they also observed the formation of wide $\gamma$-ISFs on uniaxial tensile loading to $\sim 0.002$ and $\sim 0.015$ engineering strains, respectively. Further loading (for instance, up to the ultimate tensile stress) resulted in these $\gamma$-ISFs transforming to $\varepsilon$-martensite. Similar results were obtained upon tensile loading of Fe-31Mn-5.3Si-0.8C and Fe-31Mn-8.7Si-0.8C steels, with $\gamma$-SFE $=10.5$ and $6.3 \mathrm{~mJ} / \mathrm{m}^{2}$, respectively [63].

In this study, HAADF-STEM micrographs and the $\gamma$-SFE [40] value indicate the nucleation of $\varepsilon$ martensite via $\gamma$-ISFs. Contrarily, Idrissi et al. [64] observed a higher fraction of $\gamma$-ESFs in comparison to $\gamma$-ISFs during the tensile loading of a Fe-19.7Mn-3.1Al-2.9Si steel to 0.02 true strain and proposed $\gamma$-ESF as nucleation sites for $\varepsilon$-martensite. Thus, based on the present and literature based results, we surmise that both $\gamma$-ISFs, $\gamma$-ESFs may serve as nucleation sites for $\varepsilon$-martensite.

As evidenced in Figs. $5 \mathrm{c}$ and 5 d, the lateral coarsening of deformation-induced $\varepsilon$-martensite would naturally result in their coalescing with neighbouring $\varepsilon$-martensite plates/laths; thereby increasing plate/lath thickness. This type of nucleation and coarsening mechanism was previously verified by 
Kikuchi et al. [65], wherein 1-2 nm wide $\varepsilon$-martensite laths nucleated and coalesced with neighbouring $\varepsilon$ martensite plates; thereby increasing the thickness of the latter.

Fig. 10a is a schematic illustrating how the coalescence of two fine, deformation-induced $\varepsilon$ martensite laths containing a thin region of untransformed $\gamma$ between them can occur. The passage of Shockley partial dislocations on alternate planes starting from the "C" plane of $\gamma$ and ending in the "A" plane of $\varepsilon$-martensite. Here it should be noted that this mechanism only occurs when Shockley partial dislocations pass through the configuration shown in Fig. 10a. The passage of dislocations on alternate planes through a different configuration will lead to the occurrence of the same type of planes on top of each other but is not energetically favourable.

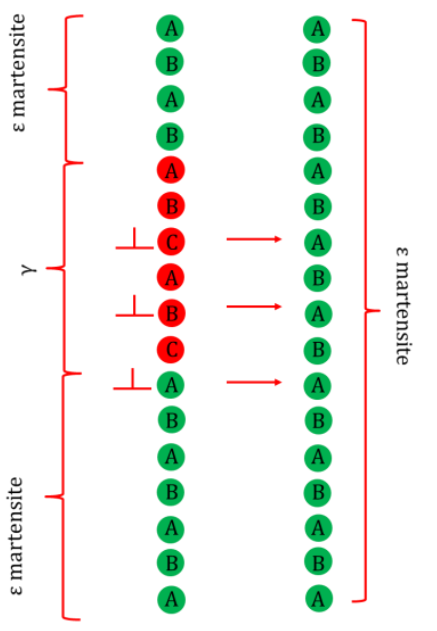

(a)

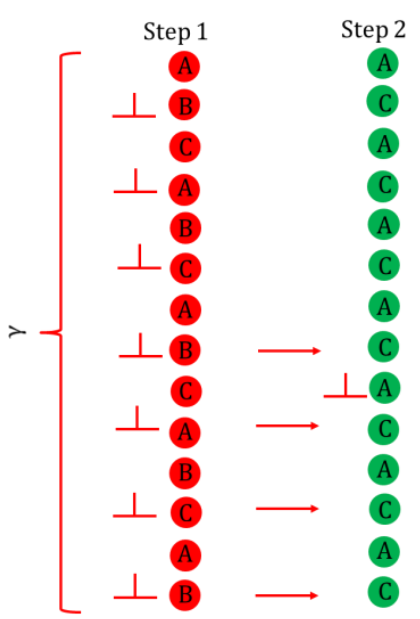

(b)

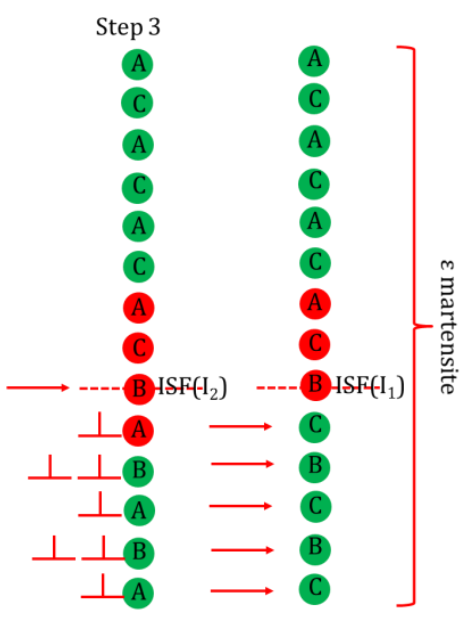

Figure 10: Schematic of (a) coarsening via coalescence of deformation-induced $\varepsilon$-martensite laths and (b) phase transformation from $\gamma$ to $\varepsilon$-martensite followed by a transition in stacking fault character from $I_{2}$ to $I_{1}$-type $\varepsilon$-ISFs. The red and green circles represent fcc and hcp stacking sequences, respectively. Shockley partial dislocations are given by the symbol " $\perp$ ”.

4.2 E-martensite: Deformation accommodation mechanisms and transition in the character of intrinsic stacking faults

The present results evidence the deformation accommodation mechanisms in $\varepsilon$-martensite as a combination of perfect and partial basal slip (Figs. 8c-8e), pyramidal slip (Fig. 8f) along with $\{10 \overline{1} 2\}\langle\overline{1} 011\rangle_{\varepsilon}$ extension twinning (Fig. 2 d, inset 2 ). $\{10 \overline{1} 2\}\langle\overline{1} 011\rangle_{\varepsilon}$ extension twinning was also observed in Fe-30Mn-6Si shape memory alloys subjected to tension [66].

$\{10 \overline{1} 2\}\langle\overline{1} 011\rangle_{\varepsilon}$ extension twinning occurs after the concomitant activation of pyramidal and basal slip [67]. In this case, the twinning dislocations in $\varepsilon$-martensite are formed by the nonplanar dissociation of a perfect basal dislocation into twinning partial dislocations in the pyramidal plane and partial basal dislocations $[68,69]$. Thus, while the generated twinning dislocations create $\{10 \overline{1} 2\}\langle\overline{1} 011\rangle_{\varepsilon}$ extension twins, the concurrently generated partial basal dislocations result in partial slip and lead to basal stacking 
faults. Thus, even the formation of $\{10 \overline{1} 2\}\langle\overline{1} 011\rangle_{\varepsilon}$ extension twins leads to basal stacking faults in $\varepsilon^{-}$ martensite.

Since the c/a ratio $=1.627$ of $\varepsilon$-martensite [24] is less than 1.633, it follows that: (i) this phase accommodates deformation by basal slip, and (ii) the dissociation of perfect dislocations into partials is relatively easy as the intrinsic stacking fault energy in the basal plane is low [70]. Consequently, the deformation of $\varepsilon$-martensite by perfect basal and partial slip is expected such that the latter leads to the generation of $\varepsilon$-ISFs.

Theoretical studies on hcp $\varepsilon$-iron have predicted basal slip as the predominant deformation mechanism [71]. In Fe-17Mn steel, dislocations with a $\langle c\rangle$ component and deformation bands were observed in $\varepsilon$-martensite [26]. $\langle c\rangle$-type dislocations have been proposed to dissociate thereby creating Shockley partial dislocations in the basal plane and thus accommodating the deformation of $\varepsilon$-martensite [26].

$\mathrm{X}$-ray diffraction analysis of a Fe-17Mn-0.02C steel subjected to uniaxial tension revealed $\mathrm{I}_{1}$ and $\mathrm{I}_{2}$ -type $\varepsilon$-ISFs [27]. In that study, the stacking fault probability of $I_{2}$-type $\varepsilon$-ISFs was found to decrease with increasing tensile strain. This was ascribed to the formation of long periodic ordered structures in $\varepsilon$ martensite that in turn, returned additional periodic spots in $\varepsilon$-martensite selected area electron diffraction patterns (for an example, refer to Fig. 7b, inset (iii) in Ref. [27]). The nomenclature of $\varepsilon$ martensite faults used in Ref. [27], which is based on a change in the stacking sequence, is opposite to that used in the present case (which was adopted from Ref. [20]). However, regardless of the difference in nomenclature, additional periodic spots corresponding to long periodic ordered structures were not observed in any $\varepsilon$-martensite diffraction patterns in this study.

In this study, multiple HAADF STEM micrographs validated the presence of $I_{1}$ and $I_{2}$-type $\varepsilon$-ISFs. While coarse $\varepsilon$-martensite plates carried over from quenching after hot-rolling did not contain stacking faults, $I_{1}$ and $I_{2}$-type $\varepsilon$-ISFs formed within $\varepsilon$-martensite grains up to $20 \%$ thickness reduction. Thereafter, only $I_{1}$-type ISFs were found at larger thickness reductions.

We summarise that the decrease in $\mathrm{I}_{2}$-type $\varepsilon$-ISFs with larger thickness reduction is more simply explained by a transition in $\varepsilon$-ISFs character from $\mathrm{I}_{2}$ to $\mathrm{I}_{1}$-type as the fine, deformation-induced $\varepsilon$ martensite laths coarsen laterally and/or coalesce with neighbouring $\varepsilon$-martensite plates/laths. In $\varepsilon$ martensite, this transition is favourable as: (i) the stacking fault probability of $I_{1}$ type $\varepsilon$-ISFs is far higher than $\mathrm{I}_{2}$-type $\varepsilon$-ISFs and, (ii) the stacking fault energy of $\mathrm{I}_{2}$-type $\varepsilon$-ISFs is higher than $\mathrm{I}_{1}$-type $\varepsilon$-ISFs. Here stacking fault energies for $\mathrm{Mg}$ (whose $\mathrm{c} / \mathrm{a}$ ratio $=1.624$ is very close to the present $\varepsilon$-martensite) also shows that the stacking fault energy associated with $\mathrm{I}_{2}$-type ISFs is higher than $\mathrm{I}_{1}$-type ISFs [20].

In this regard, we propose the schematic given in Fig. 10b to explain the transformation from $\gamma$ to $\varepsilon$-martensite and subsequent deformation accommodation by $\varepsilon$-martensite through a transition in $\varepsilon$-ISF character. In step 1, the motion of Shockley partial dislocations on every second plane leads to the phase transformation of $\gamma$ to $\varepsilon$-martensite. In step 2, the passage of a Shockley partial dislocation on the "A" stacking sequence of $\varepsilon$-martensite results in the formation of an $\mathrm{I}_{2}$-type $\varepsilon$-ISF and corresponds to initial 
plastic deformation accommodation by $\varepsilon$-martensite. In step 3 , an $\mathrm{I}_{2}$-type $\varepsilon$-ISF transitions to an $\mathrm{I}_{1}$-type $\varepsilon$-ISFs when Shockley partial dislocations pass through every plane, which also corresponds to further plastic deformation accommodation by $\varepsilon$-martensite.

It should also be highlighted that $\varepsilon$-ESFs and $\varepsilon$-twin faults were notably absent in our investigation. The absence of these two fault types is ascribed to: (i) the limitations in the observation area during HAADF STEM imaging, and (ii) their occurrence in relatively smaller fractions because of their higher energies of formation compared to $\varepsilon$-ISFs. With respect to (ii), there are one, three and two fcc-like environments in $\varepsilon$-ISF, $\varepsilon$-ESF and $\varepsilon$-twin faults, respectively. Therefore, their energies of formation follow the sequence $\mathrm{E}(\varepsilon-\mathrm{ESF}) \approx 1.5 \mathrm{E}(\varepsilon$-Twin fault $) \approx 3 \mathrm{E}(\varepsilon-\mathrm{ISF})[72]$.

\section{Conclusions}

In an Fe-17Mn-3Al-2Si-1 Ni-0.06C high $\mathrm{Mn}$ steel, room temperature plane strain compression and cold-rolling results in the generation of intrinsic stacking faults within $\gamma$ grains. The latter nucleates deformation-induced $\varepsilon$-martensite laths that subsequently coarsen laterally and coalesce with preexisting $\varepsilon$-martensite plates carried over from quenching after hot-rolling. The $\varepsilon$-martensite phase accommodates deformation via a combination of perfect and partial basal slip, pyramidal slip and $\{10 \overline{1} 2\}\langle\overline{1} 011\rangle_{\varepsilon}$ extension twinning. The activation of partial slip on the basal plane which subsequently results in basal stacking faults was also observed in $\varepsilon$-martensite. A mechanism involving the passage of Shockley partial dislocations through all planes along an $\mathrm{I}_{2}$-type intrinsic stacking fault is proposed to explain the transition in its character to an $\mathrm{I}_{1}$-type intrinsic stacking fault at higher thickness reductions in $\varepsilon$-martensite.

\section{Acknowledgements}

The authors are grateful to Prof. D.B. Santos of the Universidade Federal de Minas Gerais, Brazil for providing the source material. This work was supported by the Australian Research Council-Discovery Project (DP130101882). The JEOL JEM-2010, JEOL JEM-ARM200F and JEOL JSM-7001F were funded by Australian Research Council-Linkage, Infrastructure, Equipment and Facilities grants LE0237478, LE120100104 and LE0882613, respectively. The authors also thank Dr. Gilberto Casillas and Dr. David R.G. Mitchell for their advice on the TEM and STEM data analysis and Dr. Liang Chen for conducting the Gleeble experiments.

\section{Declaration of interest: none}

Data availability: The raw/processed data required to reproduce these findings cannot be shared at this time as the data also forms part of an ongoing study. 


\section{References}

[1] A.S. Hamada, L.P. Karjalainen, J. Puustinen, Fatigue behavior of high-Mn TWIP steels, Mater. Sci. Eng. A 517(1-2) (2009) 68-77.

[2] D. Pérez Escobar, S. Silva Ferreira de Dafé, D. Brandão Santos, Martensite reversion and texture formation in 17Mn-0.06C TRIP/TWIP steel after hot cold rolling and annealing, J. Mater. Res. Tech. 4(2) (2015) 162-170.

[3] F. Lu, P. Yang, L. Meng, F. Cui, H. Ding, Influences of thermal martensites and grain orientations on strain-induced martensites in high manganese TRIP/TWIP steels, J. Mater. Sci. Technol. 27(3) (2011) 257-265.

[4] J. Kowalska, W. Ratuszek, M. Witkowska, A. Zielińska-Lipiec, T. Tokarski, Microstructure and texture characteristics of the metastable Fe-21Mn-3Si-3Al alloy after cold deformation, J. Alloy Compd. 643, Supplement 1 (2015) S39-S45.

[5] H. Ding, H. Ding, D. Song, Z. Tang, P. Yang, Strain hardening behavior of a TRIP/TWIP steel with 18.8\% Mn, Mater. Sci. Eng. A 528(3) (2011) 868-873.

[6] L. Bracke, L. Kestens, J. Penning, Transformation mechanism of $\alpha^{\prime}$-martensite in an austenitic Fe-MnC-N alloy, Scripta Mater. 57(5) (2007) 385-388.

[7] J. Weertman, J.R. Weertman, Elementary dislocation theory, Macmillan1964.

[8] Y. Lü, D.A. Molodov, G. Gottstein, Recrystallization kinetics and microstructure evolution during annealing of a cold-rolled Fe-Mn-C alloy, Acta Mater. 59(8) (2011) 3229-3243.

[9] Y. Lü, B. Hutchinson, D.A. Molodov, G. Gottstein, Effect of deformation and annealing on the formation and reversion of $\varepsilon$-martensite in an Fe-Mn-C alloy, Acta Mater. 58(8) (2010) 3079-3090.

[10] J. Kowalska, W. Ratuszek, M. Witkowska, A. Zielińska-Lipiec, Development of microstructure and texture in Fe-26Mn-3Si-3Al alloy during cold-rolling and annealing, J. Alloy Compd. 615, Supplement 1 (2014) S583-S586.

[11] G. Frommeyer, U. Brüx, P. Neumann, Supra-ductile and high-strength manganese-TRIP/TWIP steels for high energy absorption purposes, ISIJ Int. 43(3) (2003) 438-446.

[12] Y.K. Lee, C.S. Choi, Driving force for $\gamma \rightarrow \varepsilon$ martensitic transformation and stacking fault energy of $\gamma$ in Fe-Mn binary system, Metall. Mater. Trans. A 31(2) (2000) 355-360.

[13] E. Nagy, V. Mertinger, F. Tranta, J. Sólyom, Deformation induced martensitic transformation in stainless steels, Mater. Sci. Eng. A 378(1-2) (2004) 308-313.

[14] J. Kowalska, W. Ratuszek, M. Witkowska, A. Zielińska-Lipiec, Influence of cold plastic deformation on the development of the texture in high-manganese austenitic steel, Sol. St. Phen. 203-204 (2013) 115-120. [15] A. Sato, K. Soma, T. Mori, Hardening due to pre-existing $\epsilon$-martensite in an Fe-30Mn-1Si alloy single crystal, Acta Metall. Mater. 30(10) (1982) 1901-1907.

[16] G.B. Olson, M. Cohen, A mechanism for the strain-induced nucleation of martensitic transformations, J. Less Common Met. 28(1) (1972) 107-118. 
[17] L. Bracke, K. Verbeken, L. Kestens, J. Penning, Recrystallization behaviour of an austenitic high Mn steel, Materials Science Forum 558-559 (2007) 137-142.

[18] F. Berrenberg, C. Haase, L.A. Barrales-Mora, D.A. Molodov, Enhancement of the strength-ductility combination of twinning-induced/transformation-induced plasticity steels by reversion annealing, Mater. Sci. Eng. A 681 (2017) 56-64.

[19] S. Takaki, K. Tomimura, S. Ueda, Effect of pre-cold-working on diffusional reversion of deformation induced martensite in metastable austenitic stainless steel, ISIJ Int. 34(6) (1994) 522-527.

[20] N. Chetty, M. Weinert, Stacking faults in magnesium, Phys. Rev. B 56(17) (1997) 10844-10851.

[21] D. Hull, D.J. Bacon, Introduction to dislocations, Elsevier Science 2011.

[22] A.K. De, D.C. Murdock, M.C. Mataya, J.G. Speer, D.K. Matlock, Quantitative measurement of deformation-induced martensite in 304 stainless steel by X-ray diffraction, Scripta Mater. 50(12) (2004) 1445-1449.

[23] Y.N. Wang, J.C. Huang, Texture analysis in hexagonal materials, Mater. Chem. Phys. 81(1) (2003) 1126.

[24] A.A. Gazder, A.A. Saleh, M.J.B. Nancarrow, D.R.G. Mitchell, E.V. Pereloma, A transmission Kikuchi diffraction study of a cold-rolled and annealed Fe-17Mn-2Si-3Al-1Ni-0.06C wt.\% steel, Steel Res. Int. 86(10) (2015) 1204-1214.

[25] A.A. Saleh, D.W. Brown, E.V. Pereloma, B. Clausen, C.H.J. Davies, C.N. Tomé, A.A. Gazder, An in-situ neutron diffraction study of a multi-phase transformation and twinning-induced plasticity steel during cyclic loading, Appl. Phys. Lett. 106(17) (2015) 171911.

[26] J.K. Kim, B.C. De Cooman, Observation of dislocations with a Burgers vector containing a 〈c〉 component in martensitic hcp $\varepsilon$ Fe-17\%Mn, Scripta Mater. 128 (2017) 78-82.

[27] K.H. Kwon, B.-C. Suh, S.-I. Baik, Y.-W. Kim, J.-K. Choi, N.J. Kim, Deformation behavior of duplex austenite and $\varepsilon$-martensite high-Mn steel, Sci. Technol. Adv. Mat. 14(1) (2013) 014204.

[28] K. Ogawa, S. Kajiwara, HREM study of stress-induced transformation structures in an Fe-Mn-Si-Cr-Ni shape memory alloy, Mater. Trans. 34(12) (1993) 1169-1176.

[29] S. Semiatin, T. Altan, Measurement and interpretation of flow stress data for the simulation of metalforming processes, DTIC Document, 2010.

[30] A.A. Gazder, F. Al-Harbi, H.T. Spanke, D.R. Mitchell, E.V. Pereloma, A correlative approach to segmenting phases and ferrite morphologies in transformation-induced plasticity steel using electron back-scattering diffraction and energy dispersive X-ray spectroscopy, Ultramicroscopy 147 (2014) 114132.

[31] A.A. Saleh, E.V. Pereloma, A.A. Gazder, Texture evolution of cold rolled and annealed Fe-24Mn-3Al2Si-1Ni-0.06C TWIP steel, Mater. Sci. Eng. A 528(13-14) (2011) 4537-4549.

[32] A.A. Gazder, V.Q. Vu, A.A. Saleh, P.E. Markovsky, O.M. Ivasishin, C.H. Davies, E.V. Pereloma, Recrystallisation in a cold drawn low cost beta titanium alloy during rapid resistance heating, J. Alloy Compd. 585 (2014) 245-259. 
[33] G. Palumbo, K.T. Aust, Structure-dependence of intergranular corrosion in high purity nickel, Acta Metall. Mater. 38(11) (1990) 2343-2352.

[34] J. Chen, W.N. Zhang, Z.Y. Liu, G.D. Wang, Microstructural evolution and deformation mechanism of a Fe-15Mn alloy investigated by electron back-scattered diffraction and transmission electron microscopy, Mater. Sci. Eng. A 698 (2017) 198-205.

[35] D.R.G. Mitchell, B. Schaffer, Scripting-customised microscopy tools for Digital Micrograph ${ }^{\mathrm{TM}}$, Ultramicroscopy 103(4) (2005) 319-332.

[36] L.C. Chang, H.K.D.H. Bhadeshia, Austenite films in bainitic microstructures, Mater. Sci. Tech. Ser. 11(9) (1995) 874-882.

[37] T.W. Duerig, J. Albrecht, D. Richter, P. Fischer, Formation and reversion of stress induced martensite in Ti-10V-2Fe-3Al, Acta Metall. Mater. 30(12) (1982) 2161-2172.

[38] A. Weiß, H. Gutte, P.R. Scheller, Deformation induced martensite formation and its effect on transformation induced plasticity (TRIP), Steel Res. Int. 77(9-10) (2006) 727-732.

[39] U.F. Kocks, H. Mecking, Physics and phenomenology of strain hardening: the fcc case, Prog. Mater. Sci. 48(3) (2003) 171-273.

[40] S.S.F.d. Dafé, F.L. Sicupira, F.C.S. Matos, N.S. Cruz, D.R. Moreira, D.B. Santos, Effect of cooling rate on ( $\varepsilon$, $\left.\alpha^{\prime}\right)$ martensite formation in twinning/transformation-induced plasticity Fe-17Mn-0.06 C steel, Mater. Res. 16(6) (2013) 1229-1236.

[41] W.S. Yang, C.M. Wan, The influence of aluminium content to the stacking fault energy in Fe-Mn-Al-C alloy system, J. Mater. Sci. 25(3) (1990) 1821-1823.

[42] J. Mahieu, B. C. De Cooman, J. Maki, Phase transformation and mechanical properties of Si-free CMnAl transformation-induced plasticity aided steel, Metall. Mater. Trans. A 33(8) (2002) 2573-2580.

[43] S. Vercammen, B. Blanpain, B.C. De Cooman, P. Wollants, Cold rolling behaviour of an austenitic Fe30Mn-3Al-3Si TWIP-steel: the importance of deformation twinning, Acta Mater. 52(7) (2004) 20052012.

[44] X. Li, L. Chen, Y. Zhao, R.D.K. Misra, Influence of manganese content on $\varepsilon$ - $/ \alpha^{\prime}$-martensitic transformation and tensile properties of low-C high-Mn TRIP steels, Materials \& Design 142 (2018) 190202.

[45] A.A. Gazder, A.A. Saleh, A.G. Kostryzhev, E.V. Pereloma, Application of transmission Kikuchi diffraction to a multi-phase TRIP-TWIP steel, Mater. Today: Proc. 2 (2015) S647-S650.

[46] A.A. Saleh, E.V. Pereloma, A.A. Gazder, Microstructure and texture evolution in a twinning-inducedplasticity steel during uniaxial tension, Acta Mater. 61(7) (2013) 2671-2691.

[47] J.H. Yang, C.M. Wayman, On secondary variants formed at intersections of $\epsilon$ martensite variants, Acta Metall. Mater. 40(8) (1992) 2011-2023.

[48] L. Germain, S.R. Dey, M. Humbert, N. Gey, Determination of parent orientation maps in advanced titanium based alloys, J. Microsc. 227(3) (2007) 284-291. 
[49] S.T. Pisarik, D.C. Van Aken, Crystallographic orientation of the $\varepsilon \rightarrow \alpha^{\prime}$ martensitic (athermal) transformation in a FeMnAlSi steel, Metall. Trans. A 45(8) (2014) 3173-3178.

[50] Z. Nishiyama, Martensitic transformation, Elsevier Science, USA, 2012.

[51] G. Kurdjumow, G. Sachs, Über den mechanismus der stahlhärtung, Z. Phys. 64 (1930) 325-343.

[52] W.G. Burgers, On the process of transition of the cubic-body-centered modification into the hexagonal-close-packed modification of zirconium, Physica 1(7-12) (1934) 561-568.

[53] H. Yu, Q. Dong, Z. Yao, M.R. Daymond, Stacking faults observed in $\{101-2\}$ extension twins in a compressed high Sn content Zr alloy, Scripta Mater. 141(Supplement C) (2017) 72-75.

[54] D.B. Williams, C.B. Carter, Transmission electron microscopy: a textbook for materials science, Springer, USA, 2009.

[55] S. Sandlöbes, M. Friák, S. Zaefferer, A. Dick, S. Yi, D. Letzig, Z. Pei, L.F. Zhu, J. Neugebauer, D. Raabe, The relation between ductility and stacking fault energies in $\mathrm{Mg}$ and $\mathrm{Mg}-\mathrm{Y}$ alloys, Acta Mater. 60(6) (2012) 3011-3021.

[56] B. Li, E. Ma, Pyramidal slip in magnesium: dislocations and stacking fault on the $\{1011\}$ plane, Philos. Mag. 89(14) (2009) 1223-1235.

[57] K. Guy, E. Butler, D. West, $\varepsilon$ and $\alpha^{\prime}$ martensite formation and reversion in austenitic stainless steels, J. Phys. Colloques 43(C4) (1982) 575-580.

[58] J.W. Brooks, M.H. Loretto, R.E. Smallman, In situ observations of the formation of martensite in stainless steel, Acta Metall. Mater. 27(12) (1979) 1829-1838.

[59] X.S. Yang, S. Sun, H.H. Ruan, S.Q. Shi, T.Y. Zhang, Shear and shuffling accomplishing polymorphic fcc $\gamma \rightarrow$ hcp $\varepsilon \rightarrow$ bct $\alpha$ martensitic phase transformation, Acta Mater. 136 (2017) 347-354.

[60] H. Fujita, S. Ueda, Stacking faults and fcc $(\gamma) \rightarrow$ hcp $(\epsilon)$ transformation in 18/8-type stainless steel, Acta Metall. Mater. 20(5) (1972) 759-767.

[61] E.I. Galindo-Nava, P.E.J. Rivera-Díaz-del-Castillo, Understanding martensite and twin formation in austenitic steels: a model describing TRIP and TWIP effects, Acta Mater. 128 (2017) 120-134.

[62] D.T. Pierce, J.A. Jiménez, J. Bentley, D. Raabe, C. Oskay, J.E. Wittig, The influence of manganese content on the stacking fault and austenite/ $\varepsilon$-martensite interfacial energies in $\mathrm{Fe}-\mathrm{Mn}-(\mathrm{Al}-\mathrm{Si})$ steels investigated by experiment and theory, Acta Mater. 68 (2014) 238-253.

[63] X. Tian, Y. Zhang, Effect of Si content on the stacking fault energy in $\gamma$-Fe-Mn-Si-C alloys: Part I. X-ray diffraction line profile analysis, Mater. Sci. Eng. A 516(1) (2009) 73-77.

[64] H. Idrissi, L. Ryelandt, M. Veron, D. Schryvers, P. Jacques, Is there a relationship between the stacking fault character and the activated mode of plasticity of Fe-Mn based austenitic steels?, Scripta Mater. 60(11) (2009) 941-944.

[65] T. Kikuchi, S. Kajiwara, Y. Tomota, Microscopic studies on stress-induced martensite transformation and its reversion in an Fe-Mn-Si-Cr-Ni shape memory alloy, Mater. Trans. 36(6) (1995) 719-728.

[66] X. Zhang, T. Sawaguchi, Twinning of deformation-induced $\varepsilon$-martensite in Fe-30Mn-6Si shape memory alloy, Acta Mater. 143(Supplement C) (2018) 237-247. 
[67] R.L. Bell, R. Cahn, The dynamics of twinning and the interrelation of slip and twinning in zinc crystals, P. Roy. Soc. A-Math Phy. 239(1219) (1957) 494-521.

[68] S. Mendelson, Dislocation dissociations in hcp metals, J. Appl. Phys. 41(5) (1970) 1893-1910.

[69] M.H. Yoo, J.R. Morris, K.M. Ho, S.R. Agnew, Nonbasal deformation modes of HCP metals and alloys: Role of dislocation source and mobility, Metall. Trans. A 33(13) (2002) 813-822.

[70] D.J. Bacon, V. Vitek, Atomic-scale modeling of dislocations and related properties in the hexagonalclose-packed metals, Metall. Trans. A 33(3) (2002) 721-733.

[71] J.P. Poirier, G.D. Price, Primary slip system of $\varepsilon$-iron and anisotropy of the earth's inner core, Phys. Earth Planet In. 110(3-4) (1999) 147-156.

[72] Z. Ding, S. Li, W. Liu, Y. Zhao, Modeling of stacking fault energy in hexagonal-close-packed metals, Adv. Mat. Sci. Eng. 2015 (2015) 8. 
Supplementary section

Energy dispersive spectroscopy maps showing the distribution of elements

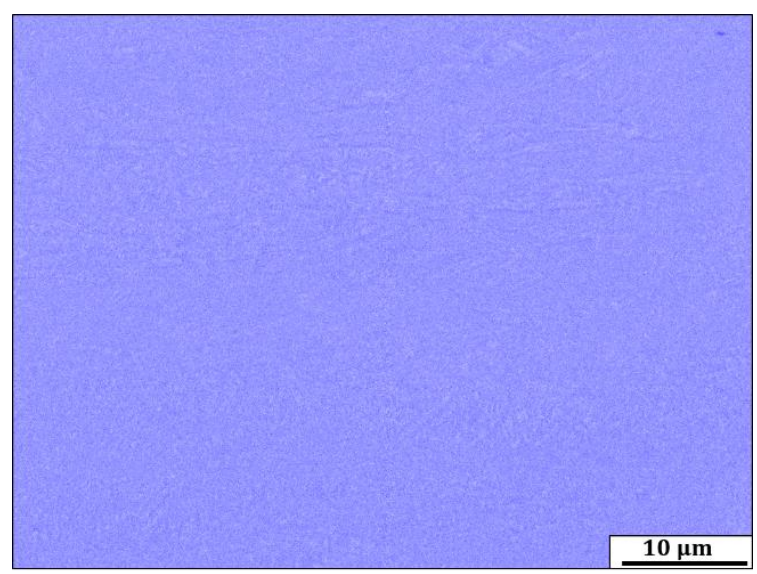

(a)

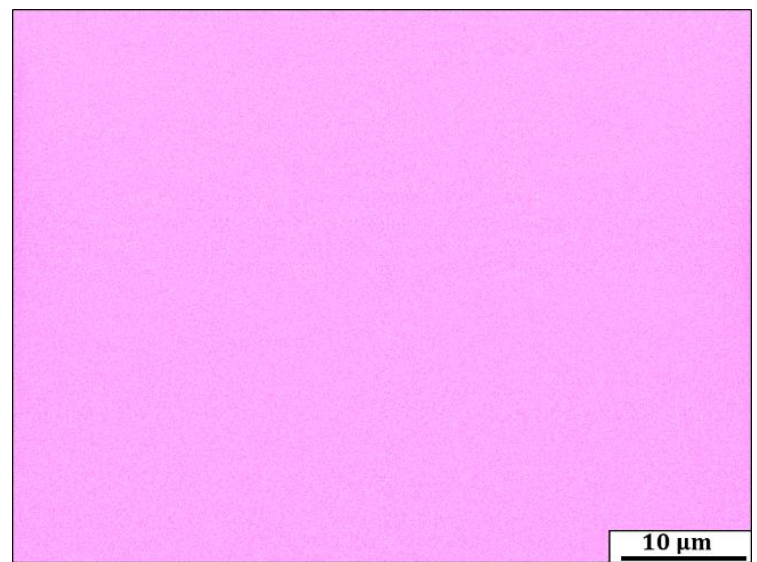

(c)

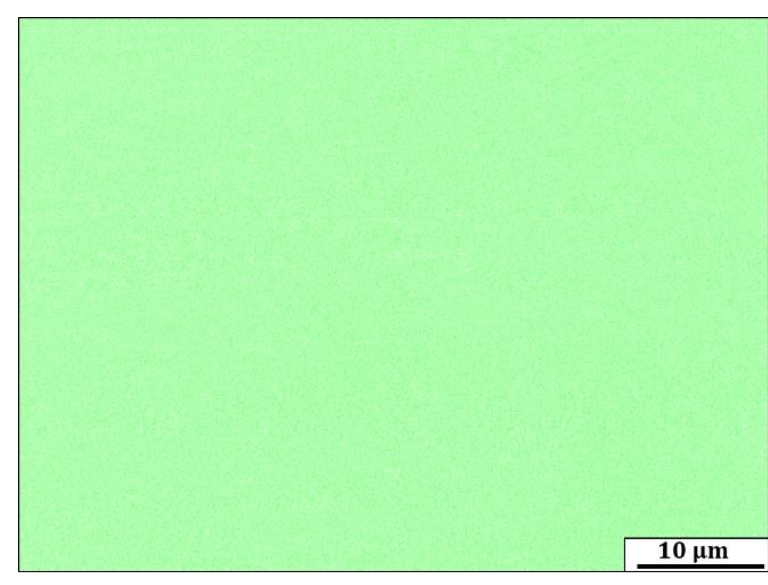

(b)

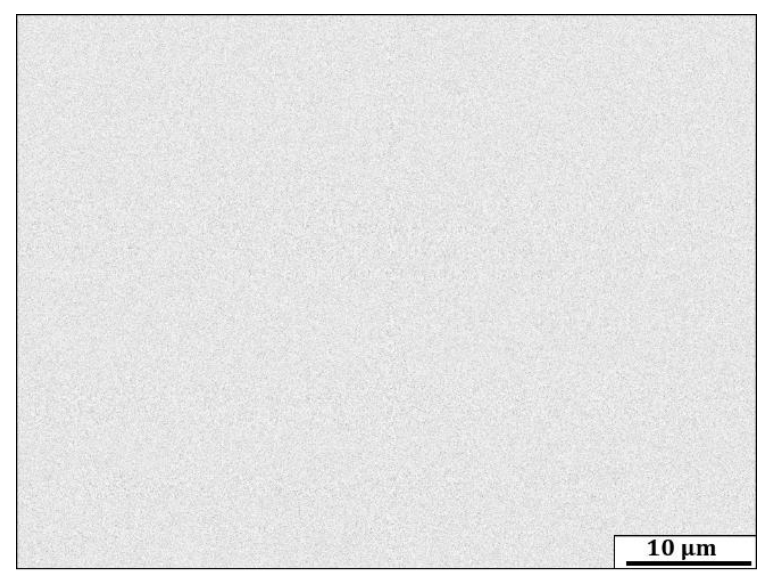

(d)

Figure S1: Energy dispersive spectroscopy maps of the $42 \%$ cold-rolled condition showing the distribution of elements (a) Mn, (b) Al, (c) Si and (d) Ni. 


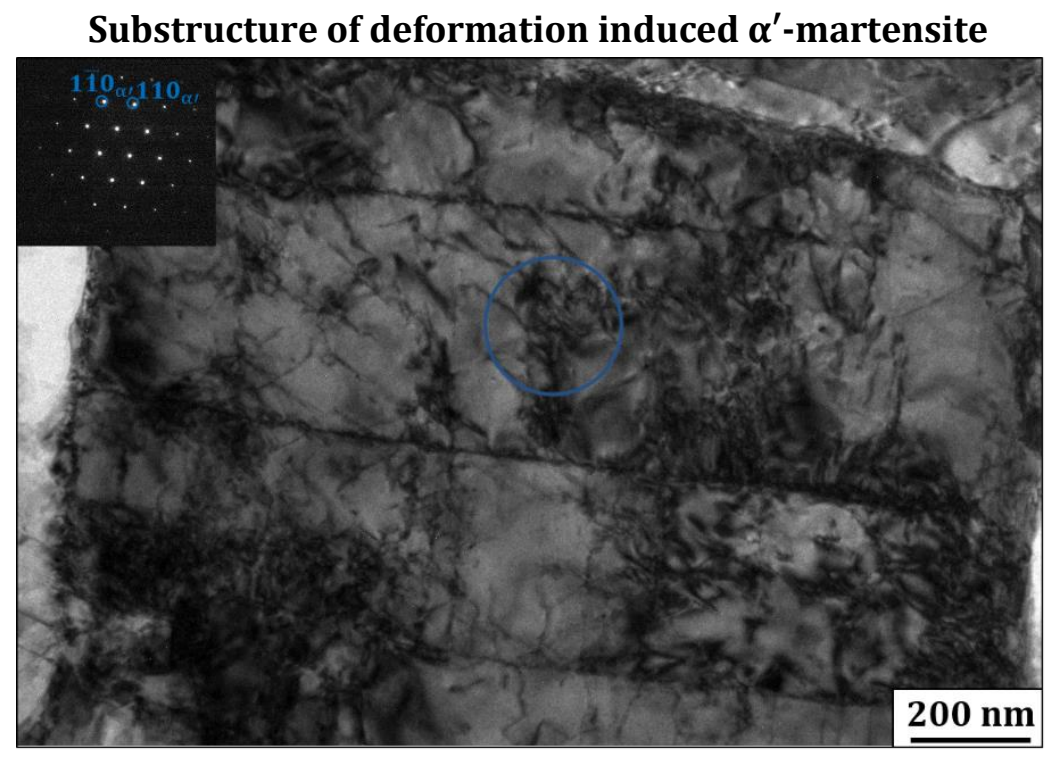

Figure S2: TEM micrograph of the sample after thickness reduction to $15 \%$ showing $\alpha^{\prime}$ martensite. The inset diffraction patterns in Fig. S2 is from the regions demarcated by a blue circle. Zone axis is $[\overline{1} 11]_{\alpha^{\prime}}$.

\section{$\varepsilon$-martensite distribution in samples after $66 \%$ and $88 \%$ thickness reduction}

The distribution of $\varepsilon$-martensite within the $\alpha^{\prime}$-martensite after thickness reduction to $66 \%$ and 88\% as shown in Fig. S3.

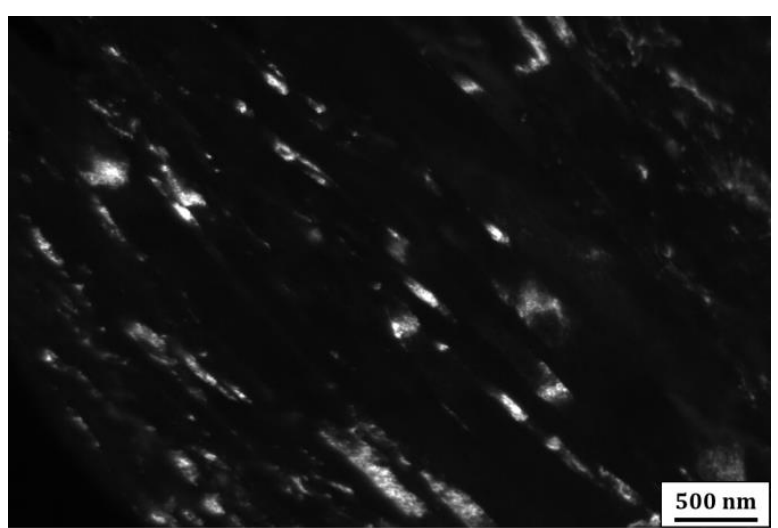

(a)

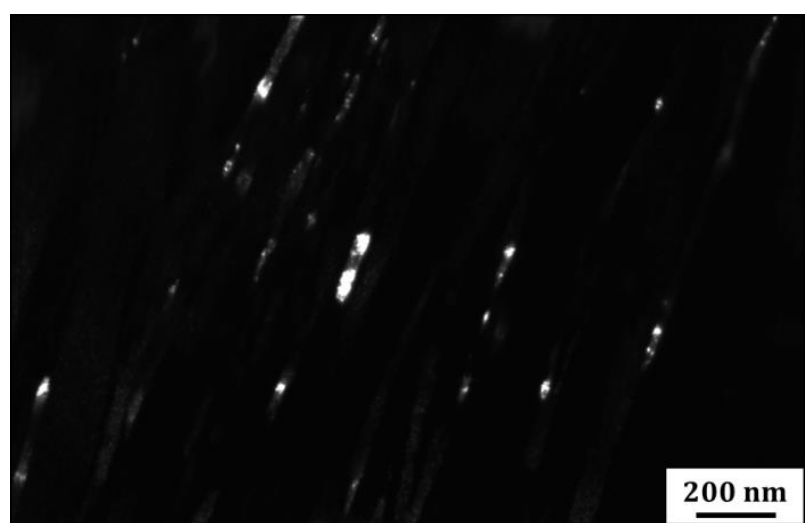

(b)

Figure S3: Dark-field images showing the $\varepsilon$-martensite distribution in samples after (a) $66 \%$ and (b) $88 \%$ thickness reduction. 


\section{Observation of stacking faults in $\boldsymbol{\gamma}$ and $\varepsilon$-martensite using two beam conditions}

The sample after 15\% thickness reduction was used to reveal the stacking faults in $\gamma$ and $\varepsilon$ martensite by the two-beam technique. The procedure outlined in Ref. [1] was employed using g $=[1 \overline{1} 1]_{\gamma}$ and $g=[01 \overline{1} 1]_{\varepsilon}$. In Figs. S4a, S4b, it can be seen that when the origin of the g-vector is placed at the center of the stacking faults in $\varepsilon$-martensite and $\gamma$ in the dark-field images taken under two beam conditions (verified by inset diffraction pattern), it is pointing away from the brighter outer fringe (highlighted by white arrows). This indicates that the faults are intrinsic in nature in $\gamma$ and $\varepsilon$-martensite.

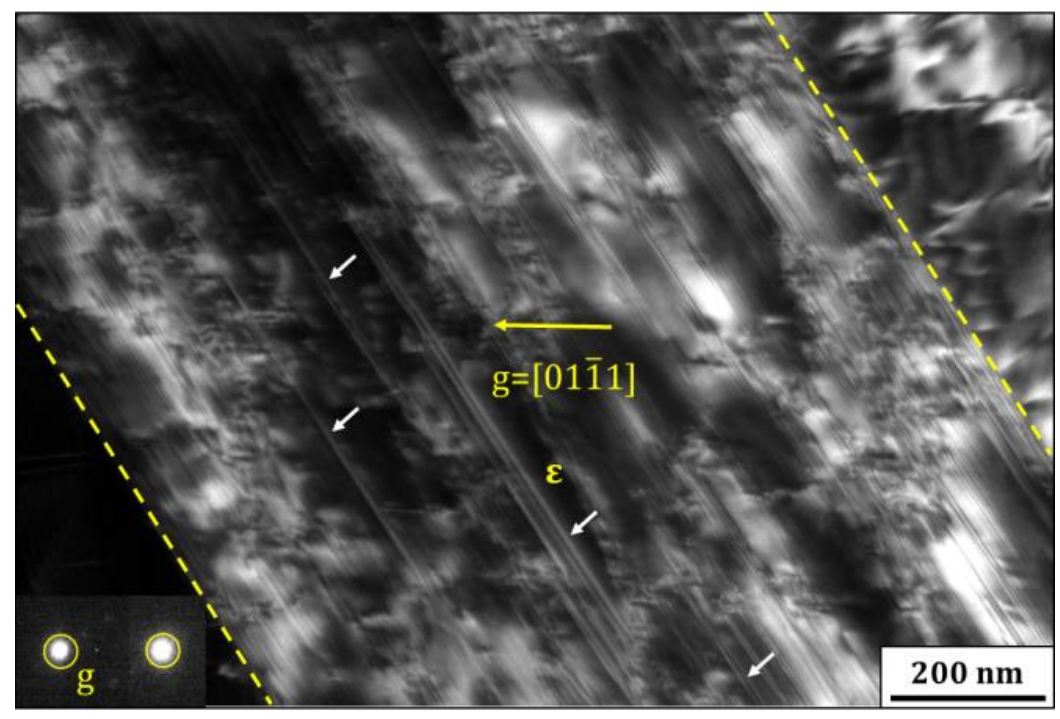

(a)

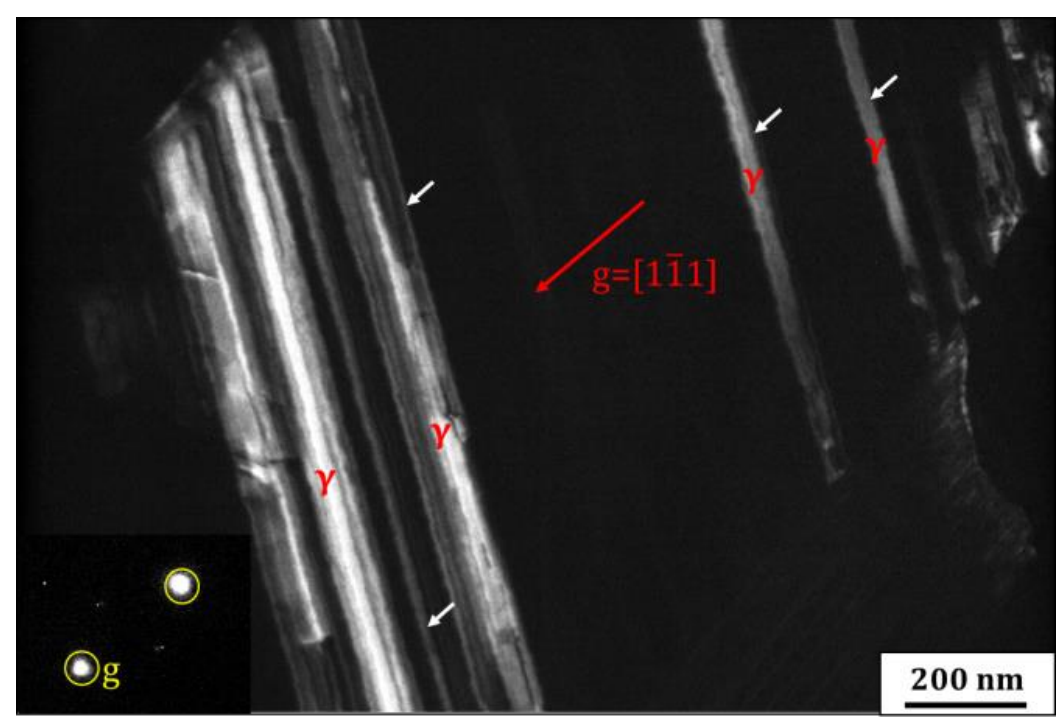

(b)

Figure S4: Dark-field image of (a) $\varepsilon$-martensite and (b) $\gamma$ in sample after $15 \%$ thickness reduction showing the presence of intrinsic stacking faults. The inset diffraction pattern in Figs. S4a, S4b shows the occurrence of two beam conditions. 


\section{Weak beam dark-field imaging of Shockley partial dislocation in $\gamma$}

Imaging of Shockley partial dislocations in $\gamma$ was carried out using weak beam dark-field (WBDF) condition. To attain WBDF condition in $\gamma$, the sample was tilted to $[111]_{\gamma}$ zone axis, respectively. Further sample tilting was undertaken to form strong two beam conditions with $\mathrm{g}$ $=[20 \overline{2}]_{\gamma}$. The beam was then tilted to bring $g$ to the centre resulting in desired g-3g condition. WBDF imaging was performed by using the reflection at the centre of the diffraction pattern.

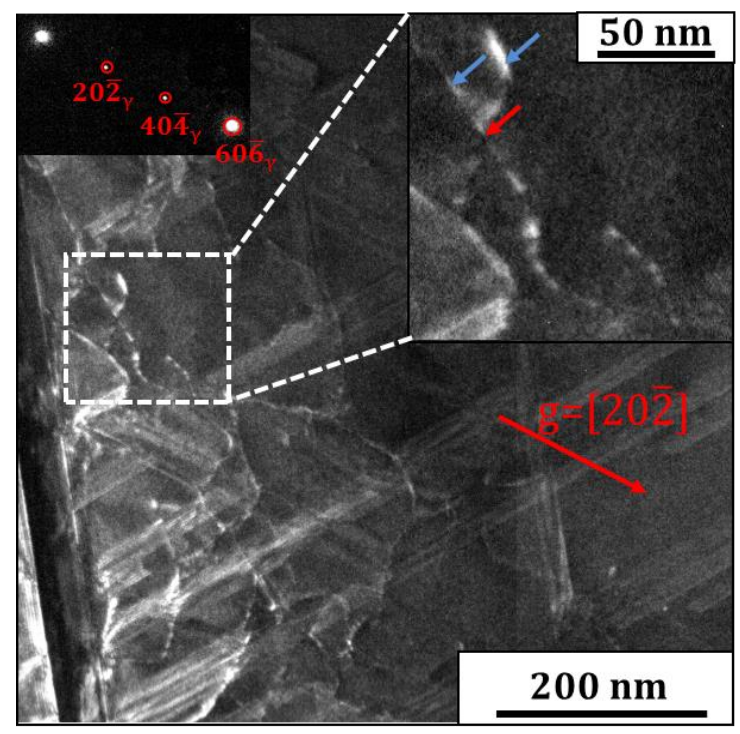

Figure S5: Representative weak beam dark-field image of $\gamma$ after 5\% thickness reduction. The inset diffraction patterns in Fig. S5 is from the regions demarcated by a white dashed rectangle in Fig. S5 using $g=[20 \overline{2}]_{\gamma}$. The red and blue arrows in Fig. S5 shows the perfect and partial dislocations. 
Supplementary Table $1 \gamma$-stacking fault energy (SFE) in high Mn steels in literature.

\begin{tabular}{|c|c|c|c|c|c|c|c|c|c|c|c|c|c|}
\hline \multirow{2}{*}{\multicolumn{5}{|c|}{ Composition (wt.\%) }} & \multirow{2}{*}{$\begin{array}{c}\gamma \text {-SFE } \\
\left(\mathrm{mJ} / \mathrm{m}^{2}\right)\end{array}$} & \multirow{2}{*}{$\begin{array}{c}\gamma-\mathrm{SFE} \\
\text { temperature }\end{array}$} & \multirow{2}{*}{$\begin{array}{c}\gamma \text {-SFE } \\
\text { determination method }\end{array}$} & \multirow{2}{*}{$\begin{array}{l}\text { Deformation } \\
\text { mode }\end{array}$} & \multirow{2}{*}{$\begin{array}{l}\text { Deformation } \\
\text { temperature }\end{array}$} & \multirow{2}{*}{$\begin{array}{c}\text { Strain rate } \\
\dot{\varepsilon}\left(s^{-1}\right)\end{array}$} & \multicolumn{2}{|c|}{ Microstructural constituents } & \multirow[t]{2}{*}{ Ref } \\
\hline $\mathrm{Mn}$ & $\mathrm{Al}$ & $\mathrm{Si}$ & & $\mathrm{C}$ & & & & & & & Before & After & \\
\hline 12 & & & & 0.6 & 11.8 & RT & Thermodynamic model & Tensile testing & RT & $10^{-3}$ & $\gamma, \varepsilon$ and $\alpha^{\prime}$-martensite & $\gamma$ twins, $\varepsilon$ and $\alpha^{\prime}$-martensite & {$[2]$} \\
\hline 12 & 1.5 & & & 0.6 & 25.5 & RT & Thermodynamic model & Tensile testing & RT & $10^{-3}$ & - & $\gamma$ twins & [2] \\
\hline 12 & 2 & & & 0.6 & 29.9 & RT & Thermodynamic model & Tensile testing & RT & $10^{-3}$ & - & - & [2] \\
\hline 15 & & & & 0.6 & 12.4 & RT & Thermodynamic model & Tensile testing & RT & $10^{-3}$ & $\gamma$ & $\gamma$ twins and $\varepsilon$-martensite & [2] \\
\hline 15 & 1.5 & & & 0.6 & 25.8 & RT & Thermodynamic model & Tensile testing & RT & $10^{-3}$ & - & $\gamma$ twins & [2] \\
\hline 15 & 2 & & & 0.6 & 30.1 & RT & Thermodynamic model & Tensile testing & RT & $10^{-3}$ & - & - & [2] \\
\hline 17 & 3 & 2 & 1 & 0.06 & 14.5 & RT & Thermodynamic model & Cold-rolling & RT & - & $\gamma, \varepsilon$ and $\alpha^{\prime}$-martensite & $\gamma, \varepsilon$ and $\alpha^{\prime}$-martensite & {$[3]^{*}$} \\
\hline 18 & & & & 0.6 & 14.3 & RT & Thermodynamic model & Tensile testing & RT & $10^{-3}$ & - & $\gamma$ twins & [2] \\
\hline 18 & & & & 0.6 & $13 \pm 3$ & RT & WBDF & Tensile testing & RT & - & $\gamma$ & - & [4] \\
\hline 18 & & & & 0.6 & 16 & RT & Thermodynamic model & Tensile testing & RT & $5 \times 10^{-3}$ & $\gamma$ & $\gamma$ twins & [5] \\
\hline 18 & & & & 0.6 & 19.3 & RT & XRD analysis & Tensile testing & RT & $10^{-4}$ & $\gamma$ & $\gamma$ twins & [6] \\
\hline 18 & & 1.5 & & 0.6 & 13.8 & RT & XRD analysis & Tensile testing & RT & $10^{-4}$ & $\gamma$ & $\gamma$ twins & [6] \\
\hline 18 & 1.5 & 0.05 & & 0.6 & 29.1 & RT & XRD analysis & Tensile testing & RT & $10^{-4}$ & $\gamma$ & $\gamma$ twins & [6] \\
\hline 18 & 1.5 & & & 0.6 & $30 \pm 10$ & RT & WBDF & Tensile testing & RT & - & $\gamma$ & - & [4] \\
\hline 18 & 1.5 & & & 0.6 & 27.5 & RT & Thermodynamic model & Tensile testing & RT & $10^{-3}$ & - & $\gamma$ twins & [2] \\
\hline 18 & 2.5 & & & 0.6 & 38 & RT & Thermodynamic model & Tensile testing & RT & $5 \times 10^{-3}$ & $\gamma$ & $\gamma$ twins & [5] \\
\hline 18 & 3 & & & 0.6 & 40.1 & RT & Thermodynamic model & Tensile testing & RT & $10^{-3}$ & - & - & [2] \\
\hline 20 & & & & 1.2 & 15 & RT & WBDF & Tensile testing & RT & - & $\gamma$ & $\gamma$ twins & [7] \\
\hline 22 & 3 & 3 & & & $15 \pm 3$ & RT & WBDF & Tensile testing & RT & $4 \times 10^{-4}$ & $\gamma$ & $\gamma, \varepsilon$ and $\alpha^{\prime}$-martensite & [8] \\
\hline 24.7 & 2.66 & 2.92 & & & $16 \pm 4$ & RT & WBDF & Tensile testing & RT & $4 \times 10^{-4}$ & $\gamma$ & $\gamma$ twins and $\varepsilon$-martensite & [9] \\
\hline 25 & 3 & 3 & & & $21 \pm 3$ & RT & WBDF & Tensile testing & $-25^{\circ} \mathrm{C}$ & $4 \times 10^{-4}$ & $\gamma$ & $\gamma, \varepsilon$ and $\alpha^{\prime}$-martensite & [8] \\
\hline 28 & 3 & 3 & & & $40 \pm 5$ & RT & WBDF & Tensile testing & $-100^{\circ} \mathrm{C}$ & $4 \times 10^{-4}$ & $\gamma$ & $\gamma$ and $\varepsilon$-martensite & {$[8]$} \\
\hline 31 & & 0.25 & & 0.96 & 17.4 & RT & XRD analysis & Tensile testing & RT & $2 \times 10^{-3}$ & $\gamma$ & - & [10] \\
\hline 32 & & 2 & & 0.64 & 14.7 & RT & XRD analysis & Tensile testing & RT & $2 \times 10^{-3}$ & $\gamma$ & - & [10] \\
\hline 31 & & 5.3 & & 0.67 & 10.5 & RT & XRD analysis & Tensile testing & RT & $2 \times 10^{-3}$ & $\gamma$ & $\gamma$ and $\varepsilon$-martensite & [10] \\
\hline 31 & & 8.7 & & 0.8 & 6.3 & RT & XRD analysis & Tensile testing & RT & $2 \times 10^{-3}$ & $\gamma$ & $\gamma$ and $\varepsilon$-martensite & [10] \\
\hline
\end{tabular}

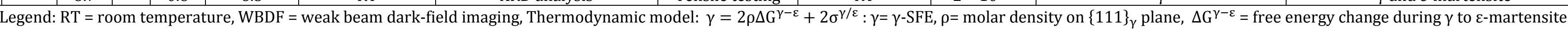

transformation, $\sigma^{\gamma / \varepsilon}=$ surface energy of $\gamma / \varepsilon$-martensite interface [11], * = present steel composition.

\section{Supplementary References}

[1] D.B. Williams, C.B. Carter, Transmission electron microscopy: a textbook for materials science, Springer, USA, 2009.

[2] J.-K. Kim, B.C. De Cooman, Stacking fault energy and deformation mechanisms in Fe-xMn-0.6 C-yAl TWIP steel, Mater. Sci. Eng. A 676 (2016) $216-231$.

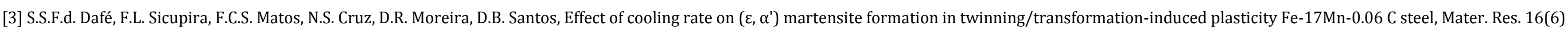
(2013) 1229-1236

[4] J. Kim, S.-J. Lee, B.C. De Cooman, Effect of Al on the stacking fault energy of Fe-18Mn-0.6C twinning-induced plasticity, Scripta Mater. 65(4) (2011) 363-366.

[5] I.-C. Jung, L. Cho, B.C. De Cooman, In situ observation of the influence of Al on deformation-induced twinning in TWIP steel, ISIJ Int. 55(4) (2015) 870-876.

[6] K. Jeong, J.-E. Jin, Y.-S. Jung, S. Kang, Y.-K. Lee, The effects of Si on the mechanical twinning and strain hardening of Fe-18Mn-0.6C twinning-induced plasticity steel, Acta Mater. 61(9) (2013) 3399-3410.

[7] H. Idrissi, K. Renard, L. Ryelandt, D. Schryvers, P.J. Jacques, On the mechanism of twin formation in Fe-Mn-C TWIP steels, Acta Mater. 58(7) (2010) $2464-2476$.

[8] D.T. Pierce, J.A. Jiménez, J. Bentley, D. Raabe, C. Oskay, J.E. Wittig, The influence of manganese content on the stacking fault and austenite/ع-martensite interfacial energies in Fe-Mn-(Al-Si) steels investigated by

experiment and theory, Acta Mater. 68 (2014) 238-253. 
[9] D.T. Pierce, J. Bentley, J.A. Jiménez, J.E. Wittig, Stacking fault energy measurements of Fe-Mn-Al-Si austenitic twinning-induced plasticity steels, Scripta Mater. 66(10) (2012) 753-756.

[10] X. Tian, Y. Zhang, Effect of Si content on the stacking fault energy in $\gamma$-Fe-Mn-Si-C alloys: Part I. X-ray diffraction line profile analysis, Mater. Sci. Eng. A 516(1) (2009) 73-77.

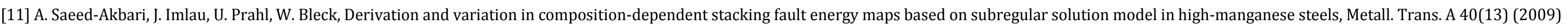

3076-3090. 
Evolution of microstructure during plane strain compression/cold-rolling
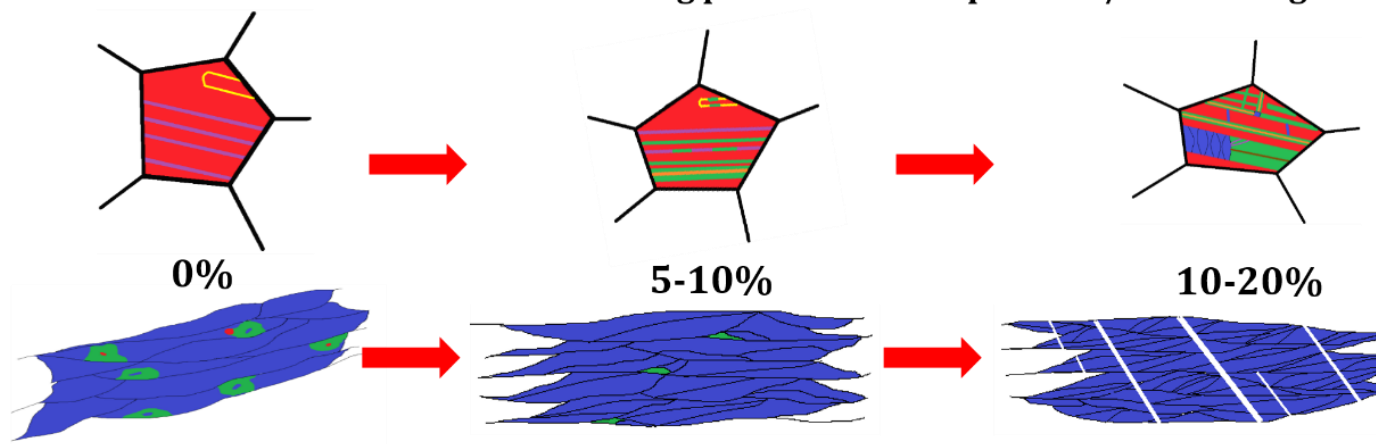

$42 \%$
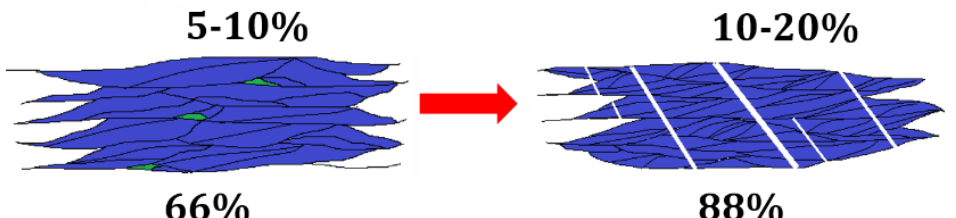

Red: $\gamma$, Blue: $\alpha^{\prime}$-martensite, Green: $\varepsilon$-martensite, Orange: $I_{2} \varepsilon$-ISFs, Brown: $I_{1} \varepsilon$-ISFs, Yellow: $\gamma$ twins, Fuchsia: $\varepsilon$-martensite twins 